\title{
Probabilistic Seismic Vulnerability Analysis of Corroded Reinforced Concrete Frames Including Spatial Variability of Pitting Corrosion
}

\author{
Ebrahim Afsar Dizaj ${ }^{a}$, Rahmat Madandoust ${ }^{b}$ and Mohammad M Kashanic* \\ ${ }^{a}$ PhD Candidate, Structural Engineering, University of Guilan, Faculty of Engineering, Rasht, \\ Iran \\ ${ }^{b}$ Associate professor, University of Guilan, Faculty of Engineering, Rasht, Iran \\ ${ }^{c}$ Associate professor, University of Southampton, Faculty of Engineering and the Environment, \\ University of Southampton, Southampton, SO17 1BJ, United Kingdom (corresponding author), \\ Email:mehdi.kashani@soton.ac.uk
}

\begin{abstract}
A probabilistic framework for seismic vulnerability analysis of corroded Reinforced Concrete (RC) frame structures is developed. An advanced nonlinear finite element modelling technique is used to accurately simulate the nonlinear behaviour of prototype corroded RC frames over their service life. Different sources of uncertainties including modelling uncertainties, geometrical uncertainties and spatial variability of pitting corrosion are considered through Monte Carlo simulation and using Latin Hypercube Sampling (LHS) technique. A set of new seismic damage limit states (SDLS) are defined accounting for multiple failure modes of the corrosion damaged frames by means of pushover analyses. The influence of corrosion on nonlinear dynamic behaviour of corroded RC frames is investigated through Incremental Dynamic Analysis (IDA) of proposed frame structures under 44 far-field ground motions. The impact of considering corrosion damaged SDLS, spatial variability of pitting corrosion, and record-to-record variability on seismic vulnerability of RC frames are explored and discussed in detail. It is concluded that disregarding the influence of corrosion on SDLS significantly underestimates the probability of failure of corroded RC frames. The analyses results show that spatial variability of pitting corrosion does not have a significant impact on global nonlinear behaviour and seismic vulnerability/reliability of corroded RC frames.
\end{abstract}

Keywords: Corrosion, Seismic damage limit state, Incremental dynamic analysis, Spatial variability; Vulnerability analysis, Fragility curve, Reinforced concrete 


\section{Introduction}

The use of carbon steel as reinforcing bars in reinforced concrete (RC) structures located in coastal regions, leading to material deterioration due to corrosion phenomenon [1]. In the recent decades, corrosion of reinforcement is recognised as the primary reason for premature deterioration of RC structures and bridges. It is reported that among the different deterioration mechanisms in RC structures, chloride attack plays the main rule with approximately $66 \%$ participation [2].

Previous experimental studies show that, at material level, corrosion reduces yield strength and ductility of reinforcing bars [3, 4], weakens bond strength between concrete and steel interfaee [5, 6] and causes premature delamination and spalling of concrete cover [7]. Moreover, according to studies conducted by Kashani et al. [8], corrosion also affects inelastic buckling behaviour and low cycle fatigue degradation of reinforcing bars. Moreover, a considerable effort has been put to understand the structural performance of corroded RC components [9-12]. All the previous studies [9-12] confirmed that corrosion reduces ultimate capacity and ductility of tested specimens.

Along with the experimental studies, several numerical models have also been developed to simulate the structural behaviour of corroded RC components [13-15]. The majority of these numerical models are based on the uniform cross sectional area reduction of reinforcing bars [13, 14] without accounting for the effect of pitting on mechanical properties of reinforcing steel and corrosion-induced damage in concrete. Dizaj et al. [16] developed a new modelling technique using nonlinear fibre beam-column element to simulate nonlinear behaviour of rectangular RC columns, and verified it against experimental test results. This model accounts for the combined effect of corrosion on mechanical properties (strength and ductility), inelastic buckling, and low cycle fatigue of reinforcing bars as well as crack cover concrete and damaged core confined concrete (due to corrosion of confining reinforcement), which is able to predict multiple failure modes of flexural RC columns.

Furthermore, chloride-induced corrosion of embedded reinforcing bars will result in reduction in structural performance of RC structures under seismic and service loads. Moreover, the coupled effect of seismic excitation and aggressive agents may result in undesired failure mechanisms during the lifetime of RC structures [15]. Therefore, many researchers have studied seismic vulnerability of corroded RC components/structures [17-21]. The outcomes of previous studies indicate that corrosion significantly reduces the structural reliability of corroded structures. However, the effect of corrosion on multiple failure modes and seismic damage limit states (SDLS) of corroded RC structures have not been included in any of previous studies. Currently, there is no model to quantify the SDLS of corroded structures/components. In all the previous studies, the fragility assessment of corroded RC structures are conducted using the SDLS of uncorroded structures [21, 22]. In a recent study by Dizaj et al. [16], it is shown that corrosion changes SDLS and failure modes of corroded RC components. Therefore, to realistically predict the long-term performance of RC structures exposed to corrosion induced degradation, there is a vital need for numerical models that account for time-variant SDLS. 
The non-uniform variation of pitting corrosion along the length of corroded reinforcing bars (spatial variability) is the primary reason for reduction in yield strength and ductility. This issue has been addressed and included in numerical models in previous studies [16], but cross section area reduction of reinforcing bars is considered to be uniform along the length of RC components. However, considering spatial distribution of pitting corrosion along the length of corroded RC components at material level might influence the global seismic vulnerability of RC structures. In other words, disregarding the spatial variability of pitting corrosion in the analyses may result in underestimating the probability of failure of corroded RC structures [23]. A number of studies have focused on reliability assessment of corroded RC members using a probabilistic distribution function to model the location of maximum pitted depth along the length of RC beams [24]. However, there has not been any study to investigate the influence of spatial variability of pitting corrosion along the length of whole structure on the seismic vulnerability of such structure.

The research presented in this paper aims to investigate the seismic vulnerability analysis of corroded RC frames through a probabilistic approach accounting for the influence of corrosion SDLS of damaged structure, and spatial variability of pitting corrosion. To this end, the previously developed Nonlinear Finite Element Model (NFEM) of corroded reetangular RC columns [16] is extended to establish a stochastic NFEM of RC frames, which accounts for the uncertainties associated with material, geometrical properties, and pitting corrosion. In the new extended model, pitting corrosion is spatially spread along the full length of beam and columns, and all the material and geometrical properties of the RC frames are considered as random variables. Using a Latin Hypercube Sampling (LHS) technique, hundred random variables, and hence, hundred NFEM are created for each analysis case (uncorroded, $5 \%, 10 \%, 15 \%$, and 20\% corrosion). The time-variant SDLS of corroded frames are quantified through a series of monotonic pushover analyses. The nonlinear dynamic behaviour of each RC frame is investigated through incremental dynamic analysis [25] of RC frames under 44 far-field ground motions, selected form FEMA P695 [26]. Finally, the time-dependent seismic vulnerability analysis of corroded RC frames considering multiple failure modes, spatial variability of pitting corrosion, and time-variant SDLS are conducted. The analyses results show that disregarding time-variant SDLS underestimates the probability of exeeedance from each SDLS for a given seismic intensity level. Furthermore, it is found that considering spatial variability of pitting corrosion increases the seismic vulnerability of corroded RC frames. The proposed model developed in this paper is currently the only available model, which accounts for multiple failure modes of corroded RC structures, considers timevariant SDLS, and considers the spatial variability of pitting corrosion across the whole length of corroded structure. 


\section{Proposed probabilistic framework}

Fig. 1 shows an overview of the proposed probabilistic framework for computing timedependent fragility curves of corroded RC frames. It should be noted that corrosion is a timedependent phenomenon, and although the time is not directly discussed in this paper, since the model is for corroded structures, it is therefore, time-dependent. The first step of developing timedependent fragility curves, is the development of a series of stochastic Nonlinear Finite Element Models (NFEM). To this end, $N$ random NFEM considering uncertainties in both material properties and spatial variability of pitting corrosion are generated using Latin Hypercube Sampling (LHS) [27] technique. Moreover, constitutive material models are modified to account for strength and ductility degradation at different point of service life of structure. The details of NEFM are available in section 4 of this paper. Since the damage limit states of uncorroded structures are not appropriate to realistically assess the failure probability of corroded structures, a series of time-dependent pushover analyses are conducted to extract time-variant SDLS of the structure. The impact of corrosion on nonlinear behaviour of corroded RC frames is investigated using Incremental Dynamic Analysis (IDA). To perform IDA, a suite of ground motions is selected and each one matched to the design spectrum. In section 5, selection and matching of the ground motions are described. Finally, time-dependent fragility curves are developed using the IDA results and the time-variant seismic damage limit states.

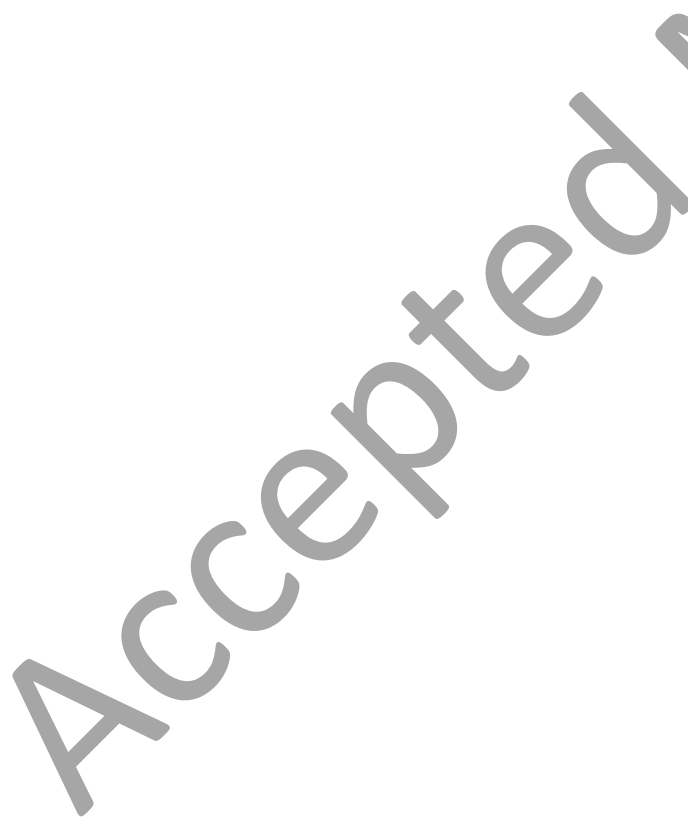




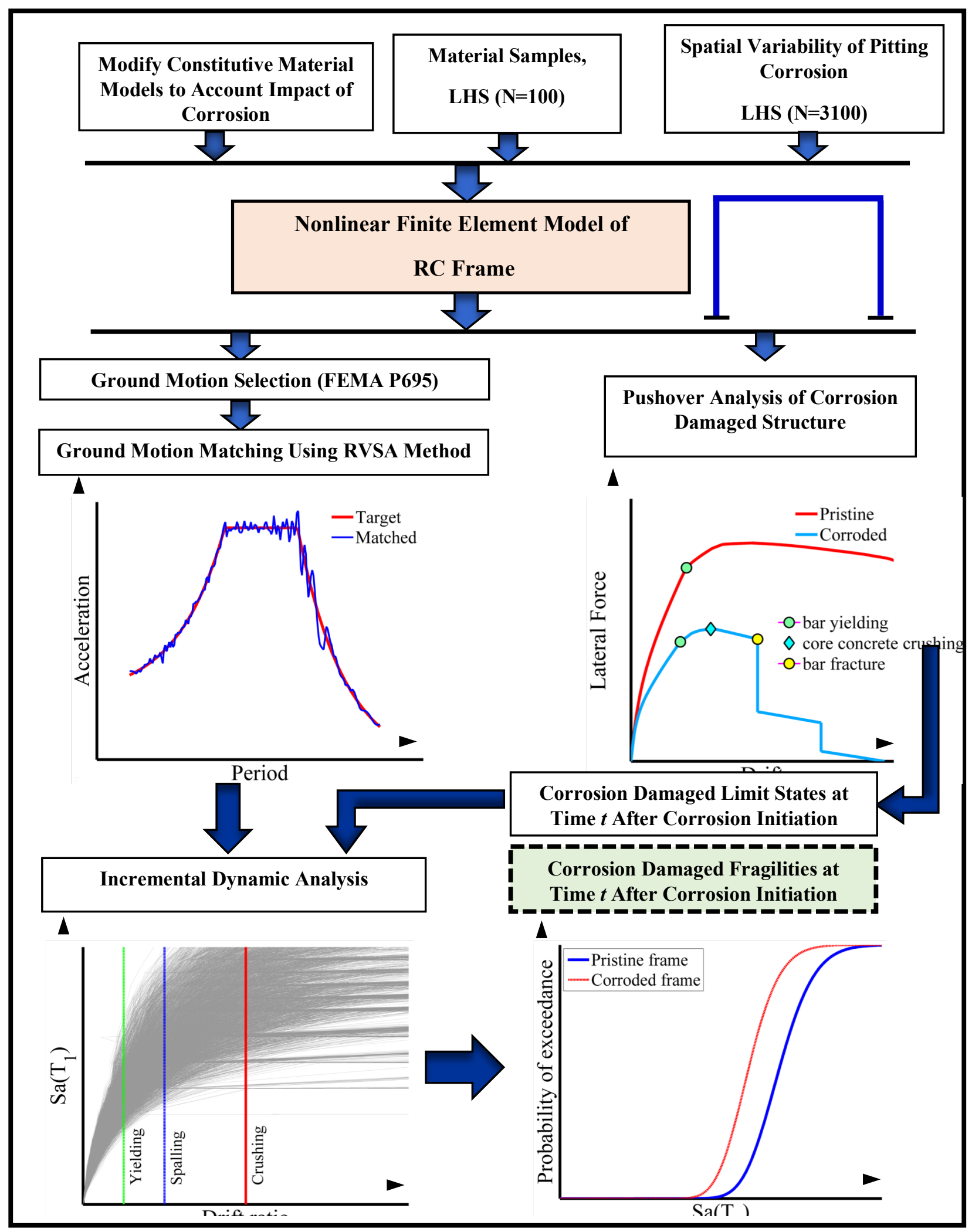

Fig. 1. Overview of the proposed probabilistic framework for fragility assessment of corrosion damaged RC frames 


\section{Design of the proposed RC frame}

Two archetypes one-storey RC frames, including a well-confined frame and a lightly-confined frame, located in Kish island in Iran, which are exposed to marine condition are designed. The structures are constructed on soil type III and located in high seismicity. According to the seismic hazard map provided in Iranian seismic design code No. 2800 [28], Kish island is a high seismic region. The proposed well-confined frame (Frame A) is designed to meet the requirements of Iranian seismic design code No. 2800 [28], ASCE 7-02 [29] and ACI 318-02 [30]. The lightlyconfined Frame B is designed to represent the existing older RC frames that can be found in Iran.

From the design dead and live loads, the equivalent axial force ratio on each column is approximately $0.05 f_{c} A_{c}$ (where $A_{c}$ is the gross cross section area of RC column, and $f_{c}$ is the concrete compressive strength).

Fig. 2 shows the details of the proposed RC frames.

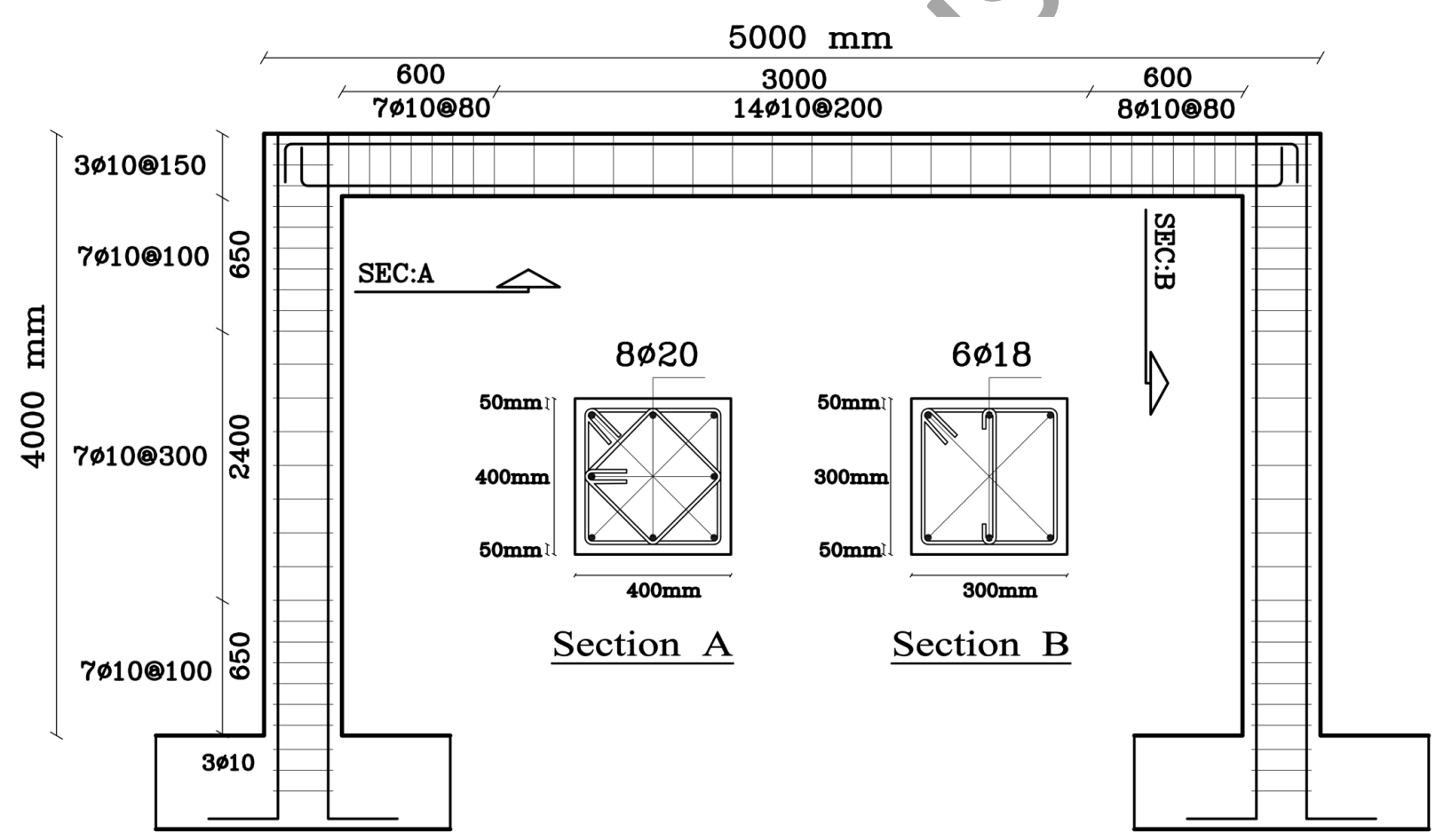

(a) 


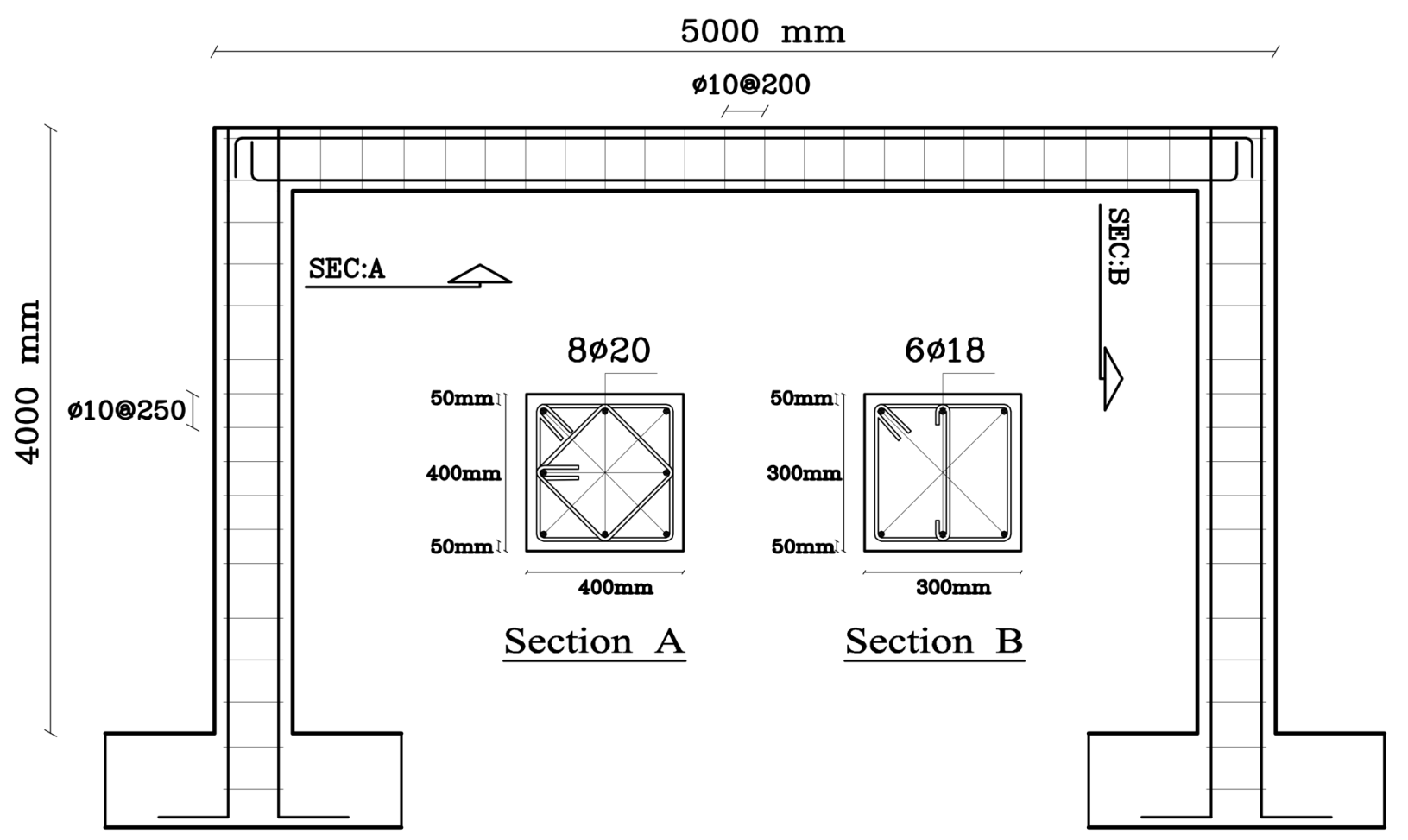

(b)

Fig. 2. Geometrical and reinforcement details of the proposed RC frames: (a) frame A - well-confined and (b) frame B - lightly-confined

\section{Description of the proposed nonlinear finite element model}

To evaluate the time-dependent structural performance of corroded RC structures during their service life, the first step is to develop a nonlinear finite element model, which is capable of modelling time-dependent structural degradation.

In recent decades, the fibre element technique [31] has been developed and extensively used in nonlinear analysis of RC structures under seismic loading. In this technique, using nonlinear fibre beam-column element, plasticity is distributed through dividing each element into several integration points along its length. The cross section of each element is divided into several fibres at integration points [31].

Dizaj et al. [16] developed a modelling technique using a nonlinear fibre beam-column element for time-dependent capacity assessment of rectangular RC columns and verified it against experimental test results. This model includes the impact of corrosion on inelastic buckling and low-cycle fatigue degradation of corroded reinforcing bars. Further details about the material modifications and experimental validation are available in [16]. The modelling technique developed in [16] is used in this study to model beams and columns of the proposed RC frames. In this study, OpenSees platform [32] is used for finite element modelling of the frames. 
Fig. 3 shows the proposed nonlinear finite element model of the RC frames. As it is shown in Fig. 3 , each column and the beam is comprised of three force-based nonlinear fibre beam-column elements according to Dizaj et al. [16]. The number of integration points along a force-based element is typically varied from three to six sections [33]. Here, the central element has 5 integration points [34]. As shown in Fig. 3, a fibre section is assigned to each integration point. Each fibre section is discretised into unconfined and confined concrete fibres as well as reinforcement fibres. To spatially distribute the pitting coefficient throughout the frame, a different pitting coefficient is randomly assigned for each fibre section which is denoted by $\alpha_{1}, \alpha_{1}, \ldots$ Further details about the spatial variability of pitting coefficient are provided in section 4.1.2.

To simulate the inelastic buckling behaviour of reinforcing bars, the buckling model developed by Kashani et al. [35] is used. This model requires the buckling length of reinforcing bars which is calculated using the methodology developed by Dhakal and Maekawa [36]. In the proposed NFEM, the integration length of the end section is adjusted to be equal to the buckling length of reinforcing bars through an additional element at each end of the component. This element is also a force-based element with a specific length and integration scheme. Further details about the calculation of buckling length and its implementation in fibre beam-column element has been discussed in detail in Kashani et al. [37] and Dizaj et al [16]. The length of each end element in

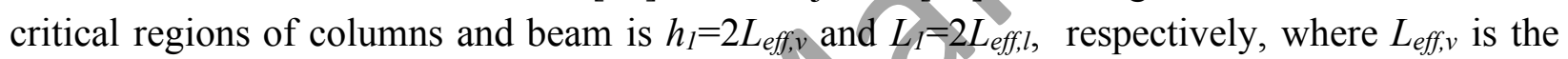
effective buckling length of vertical bars, and $L_{\text {eff, }}$ is the effective buckling length of longitudinal bars calculated using Dhakal and Maekawa [36] method. To simulate the strain penetration and slippage of the longitudinal bars, a zero-length section element section is considered at beamcolumn connections, and the base of the columns.

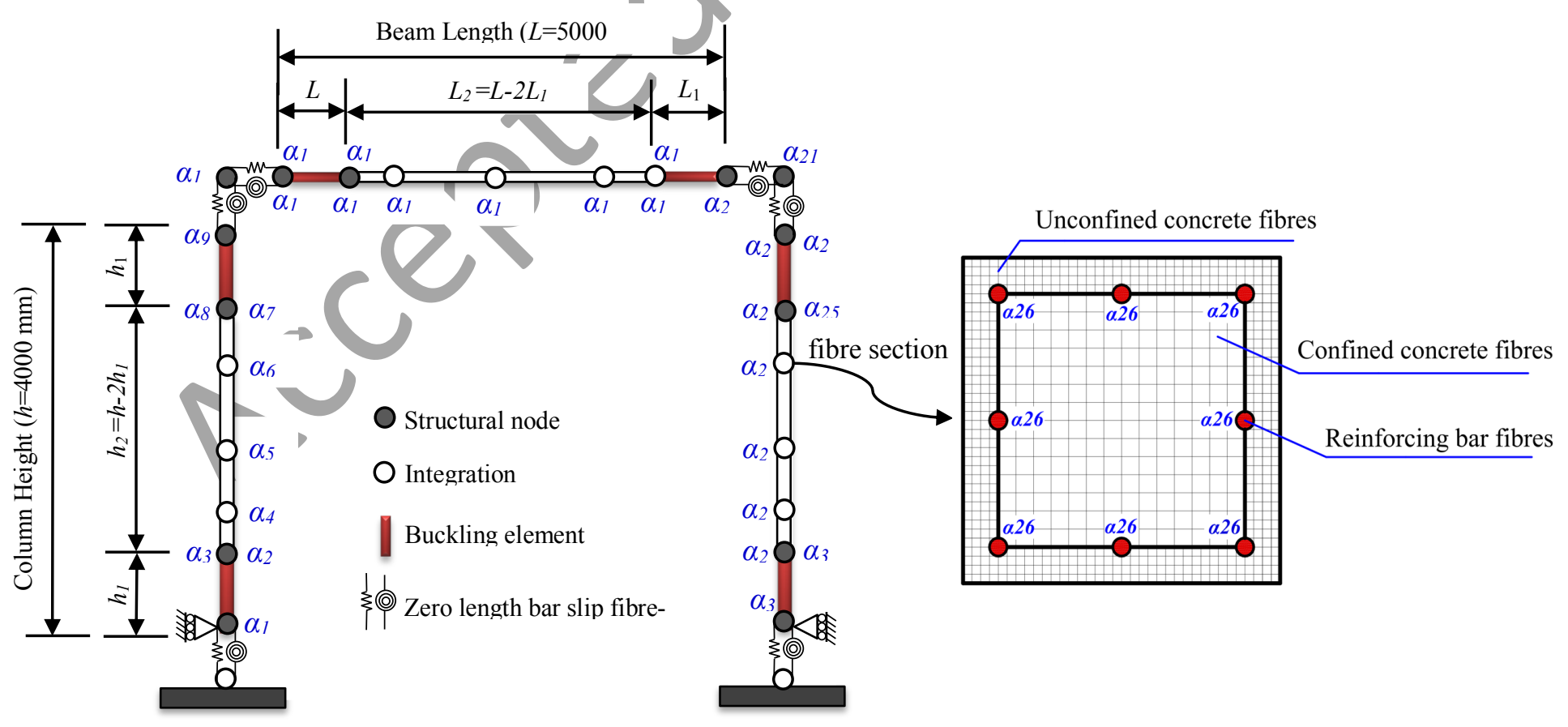

Fig 3. Proposed numerical model of RC frame 


\subsection{Modelling uncertainties associated with geometry, materials and spatial variability of pitting corrosion}

Due to inherent variability of corrosion, material properties, geometrical properties of structural components, and insufficient knowledge about the existing models, deterministic approach could not be classified as an effective method in structural safety and reliability analyses. The importance of considering epistemic uncertainties in seismic evaluation of the structures has been demonstrated in previous studies [38-39]. Therefore, uncertainties are considered via random variables of crucial parameters using specific probability distribution functions.

In this study, uncertainties are considered in analyses are considered for mechanical properties of reinforcing steel and concrete, concrete cover, diameter of reinforcement, and spatial variability of pitting corrosion, as described in the following sections 4.1.1 and 4.1.2.

\subsubsection{Uncertainties associated with materials}

Uncertainties associated with mechanical properties of materials are accounted in analyses by considering them as random variables. In this study, compressive strength of concrete $\sigma_{c}$, yield strength of longitudinal reinforcing bars $\sigma_{y}$, yield strength of horizontal ties $\sigma_{y h}$, ultimate rebar strain $\varepsilon_{u}$, and damping ratio $\xi$ are considered as random variables in the finite element model. The damping ratio is considered as a random variable, since it's value depends on multiple factors such as, geometry of the structure, structural connections etc. $[19,40]$. The uncertainties associated with geometrical properties of structural components are modelled by considering concrete cover thickness $X$, longitudinal bar diameter of beam $D_{b}$, diameter of vertical reinforcement in columns $D_{c}$, and diameter of transverse reinforcement (tie reinforcement) $D_{h}$, as random variables in the finite element model. The characterisation of proposed random variables is presented in Table 1.

Using LHS technique, one hundred random samples $(N=100)$ are generated for each random parameter, and accordingly 100 statistically different but identical NFEMs are created to perform nonlinear analyses. In other words, the material properties of the fibre sections of each generated NFEM are modified using a different set of generated random variable samples. 
Table 1. Statistical descriptors of considered random variables

\begin{tabular}{ccccc}
\hline Parameter & Mean & COV & Distribution & Reference \\
\hline $\boldsymbol{\sigma}_{\boldsymbol{c}}[\mathrm{MPa}]$ & 30 & 0.16 & Log-normal & {$[41]$} \\
\hline $\boldsymbol{\sigma}_{\boldsymbol{y}}[\mathrm{MPa}]$ & 400 & 0.05 & Log-normal & {$[42]$} \\
\hline $\boldsymbol{\sigma}_{\boldsymbol{y} \boldsymbol{h}}[\mathrm{MPa}]$ & 340 & 0.05 & Log-normal & {$[42]$} \\
\hline $\boldsymbol{X}[\mathbf{m m}]$ & 50 & 0.205 & Normal & {$[43]$} \\
\hline $\boldsymbol{D}_{\boldsymbol{b}}[\mathrm{mm}]$ & 18 & 0.02 & Normal & {$[44]$} \\
\hline $\boldsymbol{D}_{\boldsymbol{c}}[\mathbf{m m}]$ & 20 & 0.02 & Normal & {$[44]$} \\
\hline $\boldsymbol{D}_{\boldsymbol{h}}[\mathbf{m m}]$ & 10 & 0.02 & Normal & {$[44]$} \\
\hline $\boldsymbol{\xi}$ & 0.045 & 0.278 & Normal & {$[19]$} \\
\hline $\boldsymbol{\varepsilon}_{\boldsymbol{u}}$ & 0.18 & 0.09 & Normal & {$[45]$} \\
\hline
\end{tabular}

\subsubsection{Spatial variability of pitting corrosion}

In previous studies, spatial variability of pitting corrosion along the length of reinforcing bars at material level has been investigated experimentally and numerically [18, 23, 46, 47]. The main aim of previous studies was to develop a series of time-dependent probabilistic distribution functions to be used in reliability assessment of RC components and structures.

Kashani et al. [48] conducted a series of statistical analyses on the results of advanced 3D optical scanning of corroded bars. They developed a time-variant probabilistic lognormal distribution model to represent the distribution of pitting corrosion along the length of corroded bars. In this paper, this model is used to include spatial variability of pitting corrosion in nonlinear analyses. The statistical parameters of this model are tabulated in Table 2 .

Table 2. Statistical parameters of Kashani et al [48] proposed distribution model

\begin{tabular}{ccccc}
\hline Parameter & Mean & COV & Distribution & Reference \\
\hline $\boldsymbol{\alpha} \int \exp \left(\mu_{g}+\frac{\sigma_{g}^{2}}{2}\right)$ & $\left(\exp \left(2 \mu_{g}+\sigma_{g}^{2}\right)\right)\left(\exp \left(\sigma_{g}^{2}-1\right)\right)$ & Log-normal & [48] \\
$* * \mu_{g}=-0.00052 \psi^{1.825}, \sigma_{g}=0.0006491 \psi^{1.526}$ &
\end{tabular}

In this table, $\alpha$ is the pitting coefficient, which is the ratio of pitted cross section to the uniformly corroded cross section of a corroded bar at a given section [48], and $\psi$ is the percentage of mass loss of longitudinal reinforcement. The correlation between the probabilistic model parameters and pitting coefficient has been investigated and discussed in details in [48].

Using this model, and LHS technique, $N=100$ pitting coefficients $(\alpha)$ are generated for each fibre section (integration point) in columns and beams. As it is shown in Fig. 3, for each fibre section, a different pitting coefficient is randomly assigned $\left(\alpha_{1}, \alpha_{1}, \ldots\right)$, which is constant for all the bars 
in that section. Therefore, the pitting coefficient is not varied within the section. For example, a frame with $10 \%$ mass loss has 100 NFEM with varying pitting coefficients spatially distributed across the whole structure at all the integration points.

\subsection{Uniaxial material models}

\subsubsection{Reinforcing steel model}

The constitutive material model developed by Kashani et al [35] is employed to simulate the nonlinear behaviour of reinforcing steel. This model accounts for the impact of corrosion on inelastic buckling and low-cycle fatigue degradation reinforcing bars. The mechanical properties of reinforcement (yield strength ultimate strength and fracture strain) are modified through empirical equations proposed by Du et al [3]. To construct this model, the behaviour of steel in tension and compression are defined using the modelling technique developed by Kashani et al [37]. Cyclic behaviour of the considered reinforcing steel material model is shown in Fig 4.

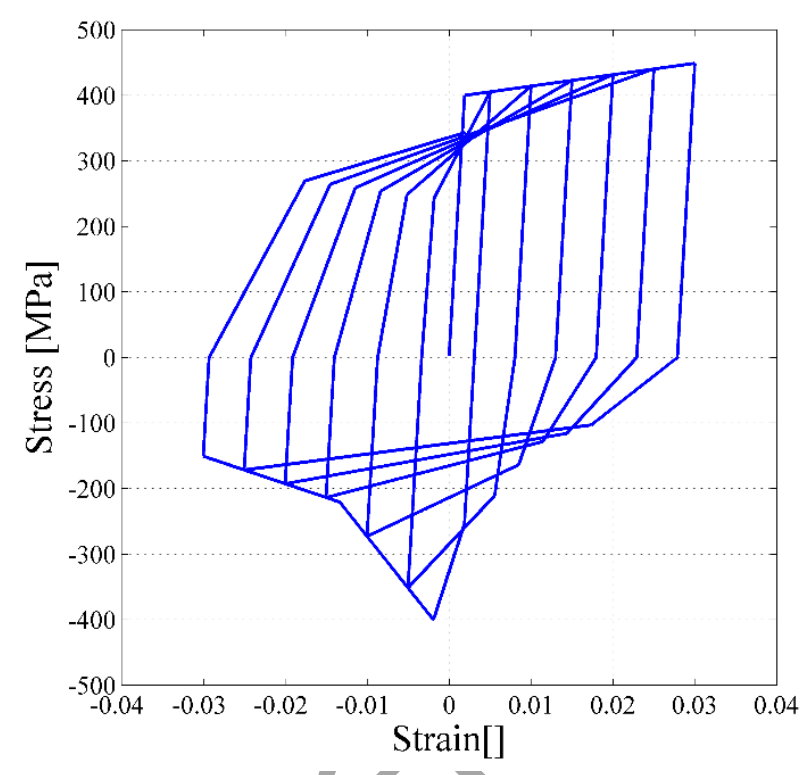

(a)

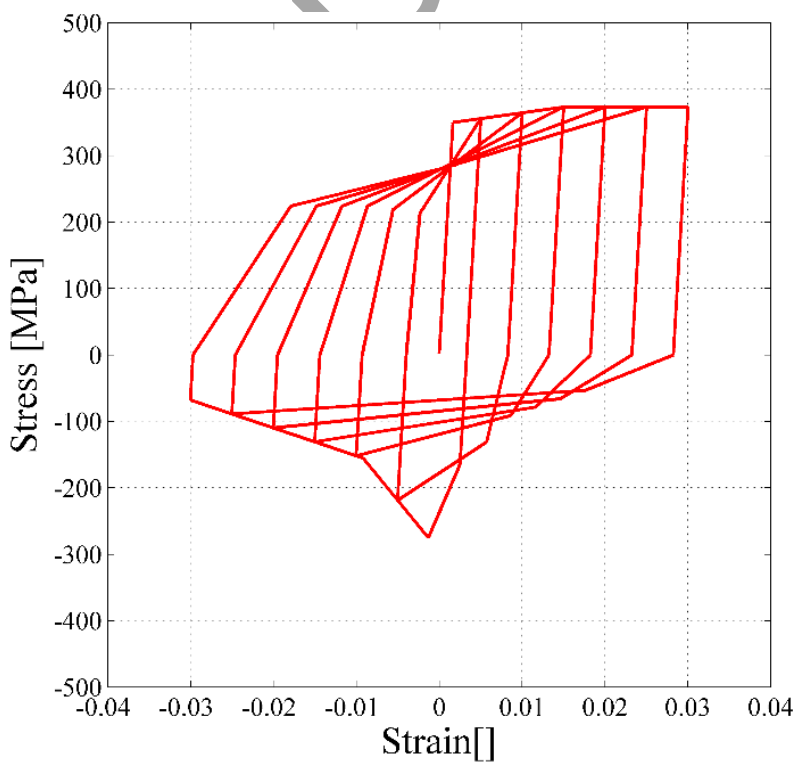

(b)

Fig 4. Cyclic behaviour of reinforcing steel material model: (a) uncorroded model and (b) corroded model with $25 \%$ mass loss

\subsubsection{Unconfined and confined concrete model}

The nonlinear behaviour of unconfined and confined concrete is modelled using uniaxial material Concrete02, available in OpenSees. To consider corrosion induced cracking and spalling of concrete cover, the compressive strength of concrete cover is reduced using the approach proposed by Coronelly and Gambarova [49]. The effect of confinements on nonlinear behaviour of core concrete is modelled using modified Kent and Park model [50]. To account for impact of corrosion of confinement reinforcement on nonlinear behaviour of confined concrete the methodology 
suggested in [51] is used, which is described in section 5 of this paper. Further details about the uniaxial material models are available in [16]. Fig. 5 shows the cyclic behaviour of considered confined concrete material model.
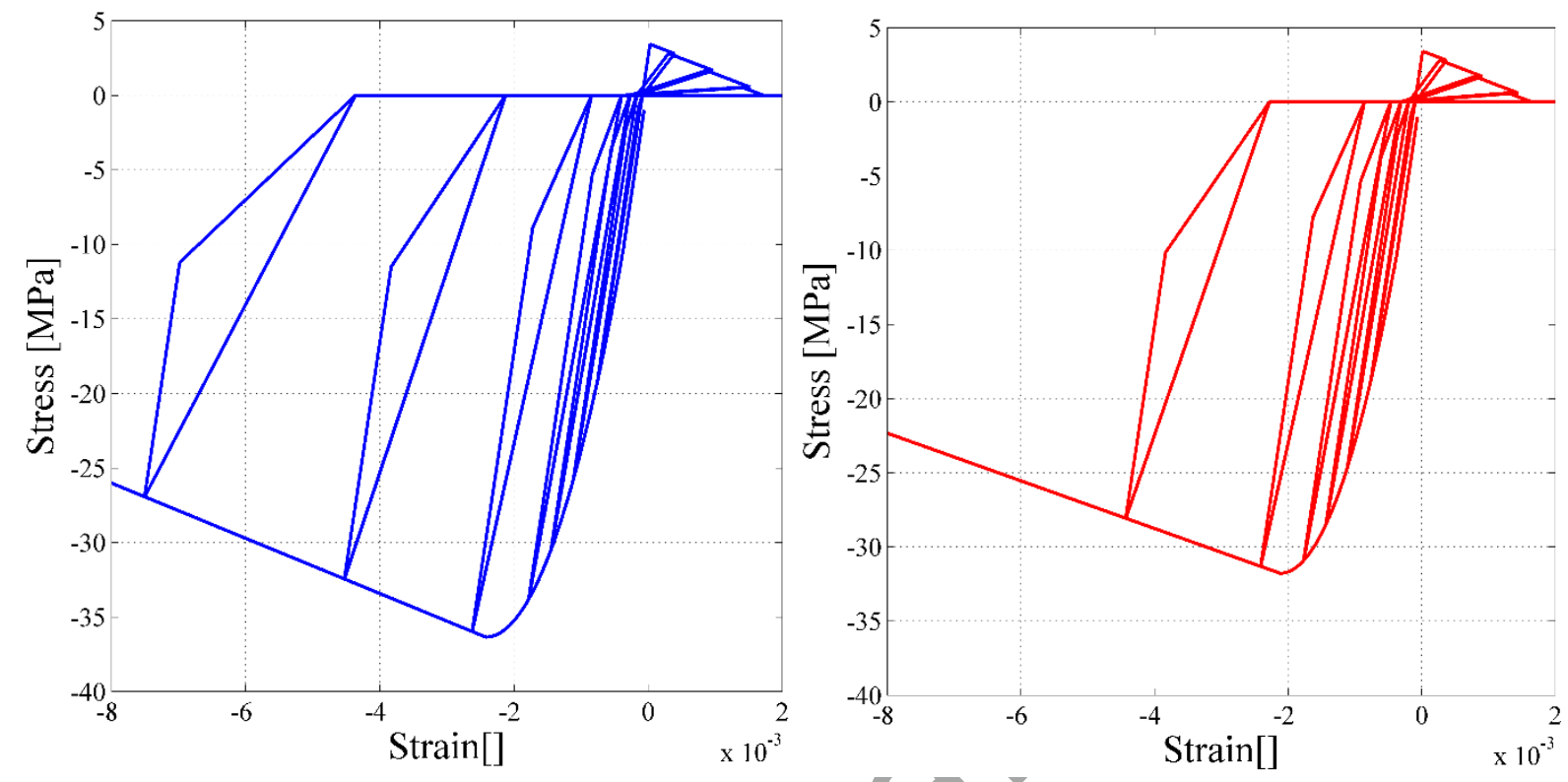

Fig 5. Cyclic behaviour of confined concrete material model: (a) uncorroded model and (b) corroded model with $25 \%$ mass loss

\subsubsection{Bar-slip model at interfaces}

The strain penetration at joint regions of RC structures results in slippage of longitudinal reinforcements and thus fixed-end rotation of flexural members. Ignoring the strain penetration in numerical modelling leads to overestimation in lateral stiffness of RC structural systems [52- 53]. To capture the strain penetration effects on overall structural response, six zero length section elements [54] are used at footings and beam-column joints (Fig. 3). The constitutive uniaxial material model proposed in [52] is used to simulate the stress-slip behaviour of reinforcing bars at member ends. In the columns footings, the uncorroded bar slip model is used as its anchorage zone is in a depth that it is unlikely to be corroded. To account for the effect of corrosion on bon-slip behaviour of beam-column joints, the original yield slip of steel in Eq.(1), developed in [52], is modified:

$S_{y}=2.54\left(\frac{d_{b, \text { corr }}}{8437} \frac{\sigma_{y, \text { corr }}}{\sqrt{\sigma_{c}}}(2 \alpha+1)\right)^{1 / \alpha}$

where $S_{y}$ is yield slip, $\alpha$ is 0.4 according to [52], $\sigma_{c}$ is compressive strength of concrete, $d_{b, c o r r}$ and $\sigma_{y, c o r r}$ are bar diameter and yield strength of corroded reinforcement according to Eq.(2) and Eq.(3), respectively:

$d_{b, \text { corr }}=d_{b} \sqrt{1-0.01 \psi}$ 


$$
\sigma_{y, \text { corr }}=\sigma_{y}(1-0.005 \psi)
$$

In these equations, $d_{b}$ and $\sigma_{y}$ are bar diameter and yield strength of uncorroded reinforcing bars, respectively and $\psi$ is percentage of mass loss. Fig 6 shows the cyclic behaviour of the considered uncorroded and corroded bar-slip material model.

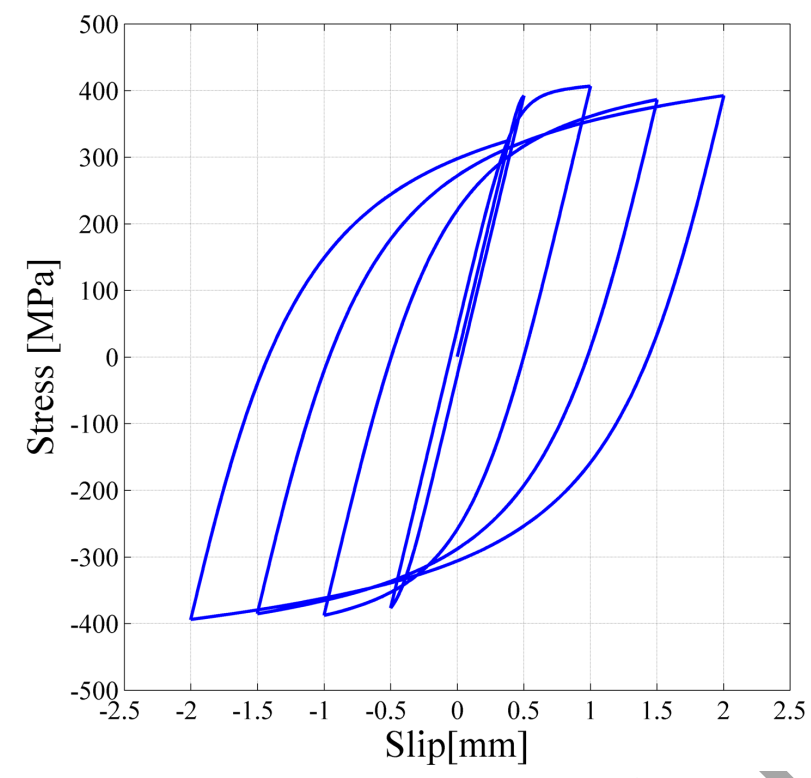

(a)

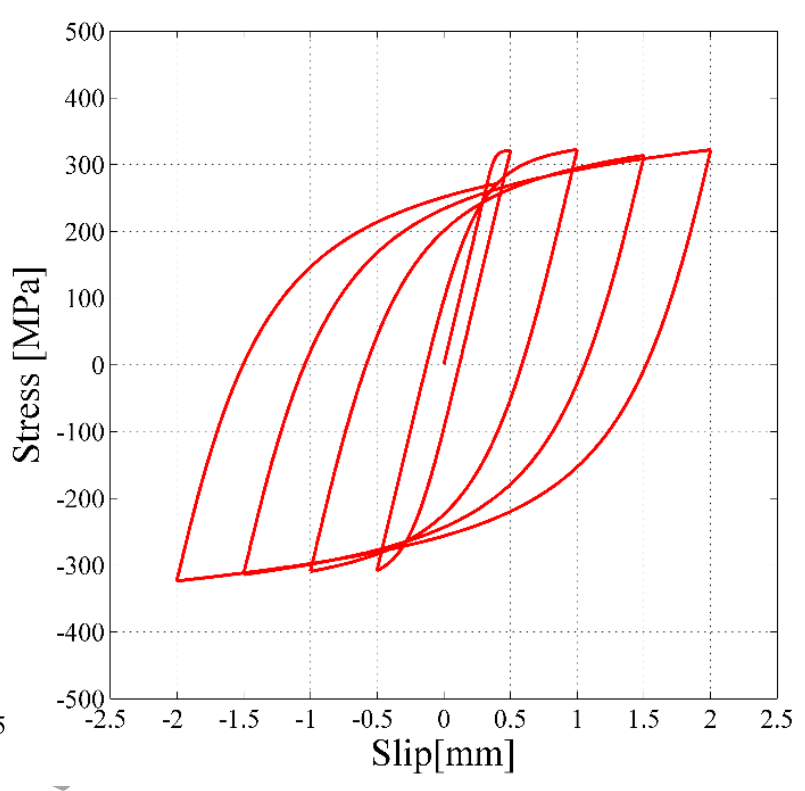

(b)

Fig 6. Cyclic behaviour of bar-slip material model: (a) uncorroded model and (b) corroded model with $25 \%$ mass loss

\section{Time-dependent seismic damage limit states}

In recent years, many studies have been conducted on seismic fragility analysis of corroded RC structures [20-22, 55, 56]. In these studies, Seismic Damage Limit States (SDLS) of uncorroded $\mathrm{RC}$ structures are used to develop fragility curves for corroded structures. However, a study conducted by Dizaj et al. [16] suggests that corrosion affects failure mode of RC structures and changes their SDLS. To accurately predict the probability of failure of corroded structures, the SDLS of corroded structures should be a function of corrosion; i.e. time-dependent. Considering SDLS of uncorroded RC structures, underestimates the probability of failure of corroded structures, and hence, unrealistic estimation of seismic fragility of such structure.

Based on the abovementioned statements, another procedure implemented here to account for time-dependent SDLS. Firstly, a series of pushover analyses are conducted on the proposedames with various corrosion levels. Therefore, an uncorroded case, and 4 different corrosion levels (5\%, 
$10 \%, 15 \%$ and $20 \%$ mass loss) are considered, and SDLS of each case are defined based on their failure mechanisms. The considered SDLS are including associated drift with yielding of vertical reinforcement, spalling of concrete cover, fracture of vertical reinforcement, and core concrete crushing. In this study, it is assumed that spalling of uncorroded column occurs when compressive strain in the extreme fibre of concrete cover exceeds 0.004 . The concrete spalling strain for corroded columns are modified using the model suggested by Coronelli and Gambarova [49].

The fracture strain of vertical reinforcement $\varepsilon_{u, c o r r}$ can be obtained from the Eq.(4) [3]:

$$
\varepsilon_{u, \text { corr }}=[1-0.05 \psi] \varepsilon_{u, 0}
$$

Where, $\psi$ is percentage of mass loss and $\varepsilon_{u, 0}$ is ultimate strain of uncorroded reinforcements.

The crushing strain of core concrete is considered as the strain at onset of fracture of transverse reinforcement according to Eq. (5).

$$
\varepsilon_{c u}=0.004+1.4\left[\frac{\rho_{s} \sigma_{y h} \varepsilon_{u h}}{\sigma_{c c}}\right]
$$

where, $\varepsilon_{u h}$ is strain at maximum stress of ties, $\sigma_{c c}$ is compressive strength of confined concrete, and $\rho_{s}$ is volumetric ratio of ties. According to modified Kent and Park model [50], $\sigma_{c c}$ is calculated using Eq. (6):

$\sigma_{c c}=K_{c} \sigma_{c}$

where $K_{c}$ is calculated using Eq. (7):

$K_{c}=1+\frac{\rho_{s} \sigma_{y h}}{\sigma_{c}}$

The parameters of Eq. (5) are modified for corroded frames with $\psi_{t i e}$ (percentage of mass of corroded ties) using the methodology suggested by Kashani et al. [35, 51]:

$$
\begin{aligned}
& \rho_{s}=\left[1-0.01 \psi_{\text {tie }}\right] \rho_{s, 0} \\
& \sigma_{y h}=\left[1-0.005 \psi_{t i e}\right] \sigma_{y h, 0} \\
& \varepsilon_{u h}=\left[1-0.05 \psi_{t i e}\right] \varepsilon_{u h, 0}
\end{aligned}
$$

where $\rho_{s, 0}, \sigma_{y h, 0}$ and $\varepsilon_{u h, 0}$ are the corresponding parameters of uncorroded ties.

Fig. 7 shows the results of pushover analyses. As can be seen in Fig. 7, in all cases, the well confined frame shows more ductile behaviour in comparison with lightly confined frame. For example, in $15 \%$ and $20 \%$ mass losses the failure mechanism of well confined frame is core concrete crushing followed by fracture of vertical bars, and the failure mode of lightly confined 
frame is governed by core concrete crushing. This is due to the lack of confinement in lightly confined frame. According to Fig. 7 (a), the associate drift of reinforcement yielding and cover spalling of uncorroded frame are approximately $1 \%$ and $3 \%$, respectively which are in good agreement with the recommended values in HAZUS-MH MR5 [57]. It should be noted that the pushover analyses of corroded frames are conducted considering the uniform corrosion of reinforcing bars.

The time-variant SDLS are estimated using the results of pushover analyses and tabulated in Tables 3 and 4.

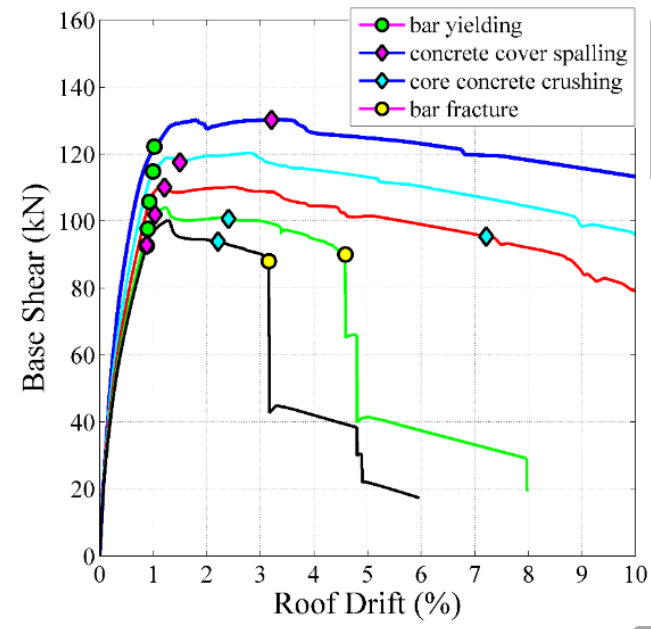

(a)

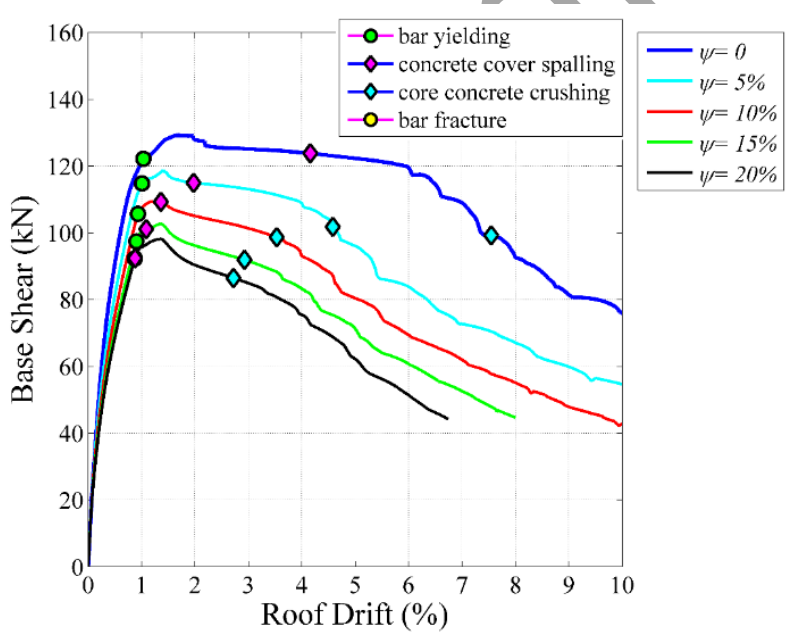

(b)

Fig. 7. Time-dependent pushover anâlyses: (a) well confined frame, and (b) lightly confined frame

Table 3. Influence of corrosion on SDLS of well-confined frame

\begin{tabular}{ccccc}
\hline $\begin{array}{c}\text { corrosion } \\
\text { level }\end{array}$ & $\begin{array}{c}\text { drift at } \\
\text { bar } \\
\text { yielding }\end{array}$ & $\begin{array}{c}\text { drift at } \\
\text { cover } \\
\text { spalling }\end{array}$ & $\begin{array}{c}\text { drift at core concrete } \\
\text { crushing }\end{array}$ & $\begin{array}{c}\text { drift at } \\
\text { bar } \\
\text { fracture }\end{array}$ \\
\hline $\boldsymbol{\psi}=\mathbf{0}$ & 0.010 & 0.032 & 0.08 & - \\
\hline $\boldsymbol{\psi}=\mathbf{5 \%}$ & 0.010 & 0.015 & 0.08 & - \\
\hline $\boldsymbol{\psi = \mathbf { 1 0 } \%}$ & 0.009 & 0.012 & 0.072 & 0.046 \\
\hline $\boldsymbol{\psi = \mathbf { 1 5 \% }}$ & 0.009 & 0.010 & 0.024 & 0.031 \\
\hline $\boldsymbol{\psi}=\mathbf{2 0} \%$ & 0.0087 & 0.0087 & 0.022 & \\
\hline
\end{tabular}


Table 4. Influence of corrosion on SDLS of lightly-confined frame

\begin{tabular}{ccccc}
\hline $\begin{array}{c}\text { corrosion } \\
\text { level }\end{array}$ & $\begin{array}{c}\text { drift at } \\
\text { bar } \\
\text { yielding }\end{array}$ & $\begin{array}{c}\text { drift at } \\
\text { cover } \\
\text { spalling }\end{array}$ & $\begin{array}{c}\text { drift at core concrete } \\
\text { crushing }\end{array}$ & $\begin{array}{c}\text { drift at } \\
\text { bar } \\
\text { fracture }\end{array}$ \\
\hline $\boldsymbol{\psi}=\mathbf{0}$ & 0.010 & 0.032 & 0.075 & - \\
\hline $\boldsymbol{\psi}=\mathbf{5 \%}$ & 0.010 & 0.015 & 0.046 & - \\
\hline $\boldsymbol{\psi = \mathbf { 1 0 } \%}$ & 0.009 & 0.012 & 0.035 & - \\
\hline $\boldsymbol{\psi = \mathbf { 1 5 } \%}$ & 0.009 & 0.010 & 0.029 & - \\
\hline $\boldsymbol{\psi}=\mathbf{2 0} \%$ & 0.0087 & 0.0087 & 0.027 & \\
\hline
\end{tabular}

\section{Influence of corrosion on nonlinear dynamic behaviour of the RC frame}

The impact of corrosion on nonlinear dynamic behaviour of the RC frame is evaluated through incremental dynamic analysis (IDA) [25]. IDA is a nonlinear dynamic analysis method which enables the prediction of structural damage in terms of earthquake intensity. To consider the inherent uncertainty in frequency content and spectral shape of earthquakes, a sufficient number of ground motions should be selected and each one scaled by increasing scale factors so that the structure experiences different ranges of behaviour from elastic to collapse.

\subsection{Ground motion selection and matching}

Due to lack of enough population of recorded ground motions in Iran, a set of 44 (22 pairs) farfield ground motions provided in FEMA P695 [26] is employed to be used in nonlinear dynamic analyses. This set contains a variety of records with peak ground acceleration from $0.21 \mathrm{~g}$ to $0.82 \mathrm{~g}$ and peak ground velocity from $19 \mathrm{~cm} / \mathrm{sec}$ to $115 \mathrm{~cm} / \mathrm{sec}$ and different soil types, class D and class C sites. Using Reweighted Volterra Series Algorithm (RVSA) [58] the selected ground motions, are matched to the design spectrum of the frames which is classified as soil type 3 spectrum in Iranian seismic provisions code No. 2800 [28]. The RVSA keeps time point of main pulses, general envelope and frequency content of original ground motion unchanged, and separate out the stationary and nonstationary content of ground motion. Further details about this algorithm are provided in [58]. Fig. 8(a) shows the elastic response spectra of selected ground motions and the design response spectrum, and Fig. 8 (b) shows the matched response spectra of selected ground motions to the design response spectrum.

Since the main objective of this study is to investigate the impact of corrosion and spatial variability of pitting corrosion on nonlinear dynamic response of corroded RC frames, the matched ground motions are used herein to perform IDA, which will reduce the record-to record variability. 
investigation of the mean response was one of the main objective of this study, and authors believe that the method worked well to achieve this objective.

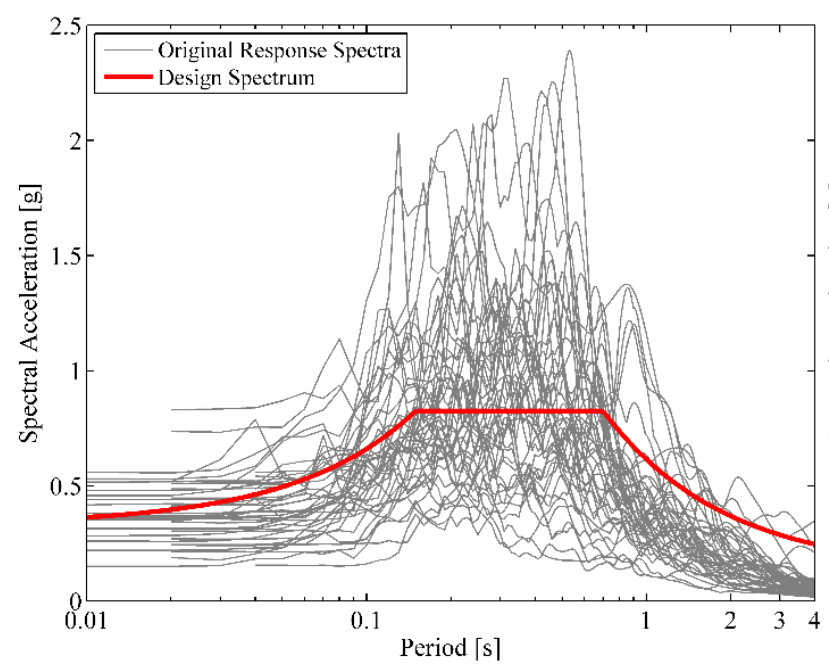

(a)

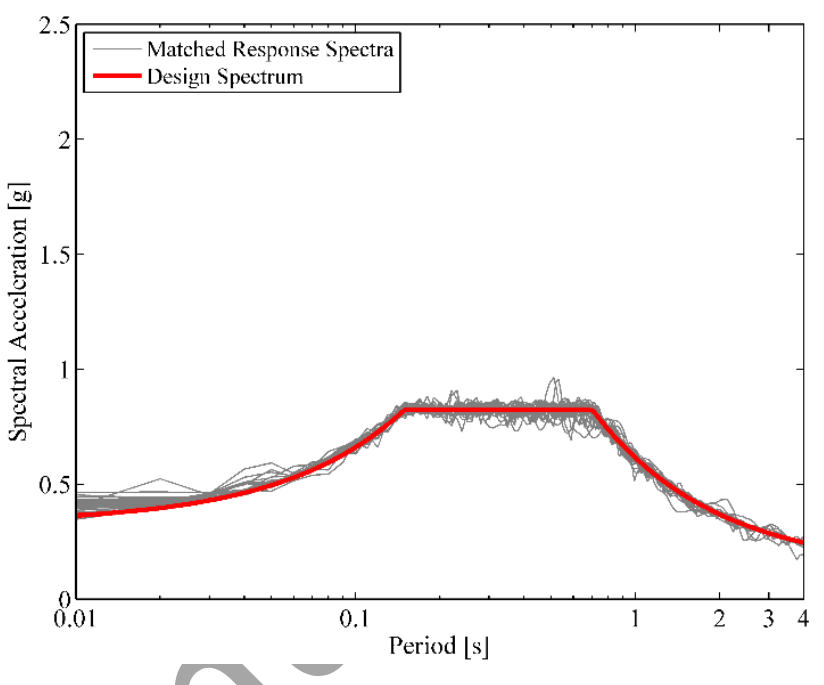

(b)

Fig. 8. Response spectra of selected records versus design spectrum: a) original records; b) matched records

\subsection{Results of IDA and discussion}

Using the 44 ground motions, and 100 different combinations of random variables, 4400 IDA curves is obtained for each frame at each analysis case. Fig. 9 shows the example IDA results for uncorroded frame and a corroded frame with $20 \%$ mass loss. In each graph, in addition to 4400 individual curves, the mean IDA curves and standard deviations are also plotted to show the dispersion of results. According to Fig. 9, IDA graphs are very scattered, and behaviour of the structure is significantly dependent on input ground motion time series.

The median IDA curve of each frame is shown in Fig. 10. According to Fig. 10, the maximum acceleration response $(\mathrm{Sa})$ of the frames decreases as corrosion level increases. For example, while the maximum response acceleration capacity of uncorroded frame is approximately $1.8 \mathrm{~g}$, it is dropped to $1.3 \mathrm{~g}$ in $10 \%$ corroded frame, which shows approximately $28 \%$ reduction in the maximum response. The maximum response of $20 \%$ corroded frame is significantly reduced in comparison with uncorroded frame (approximately $39 \%$ reduction). 


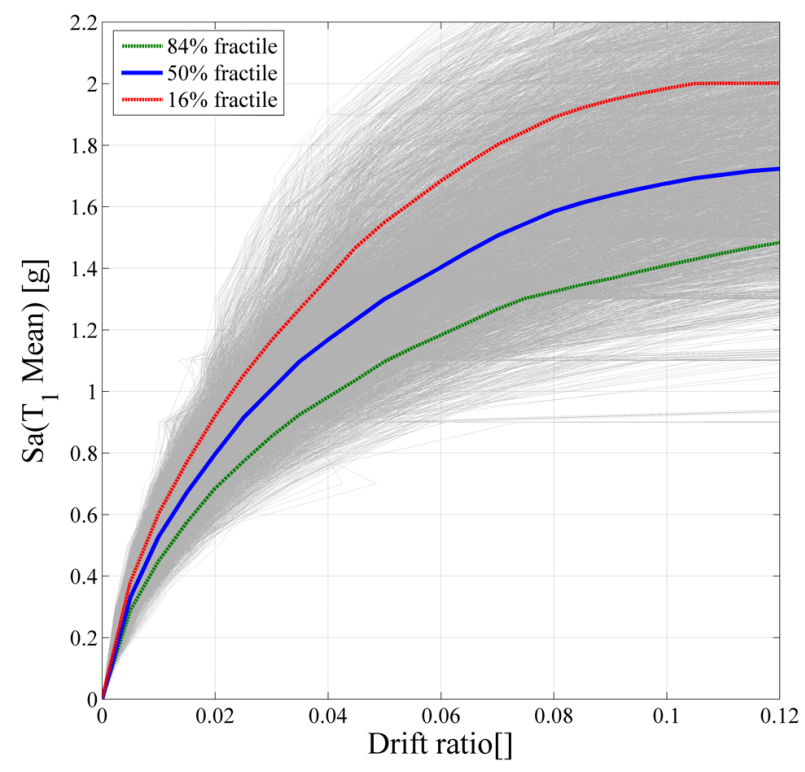

(a)

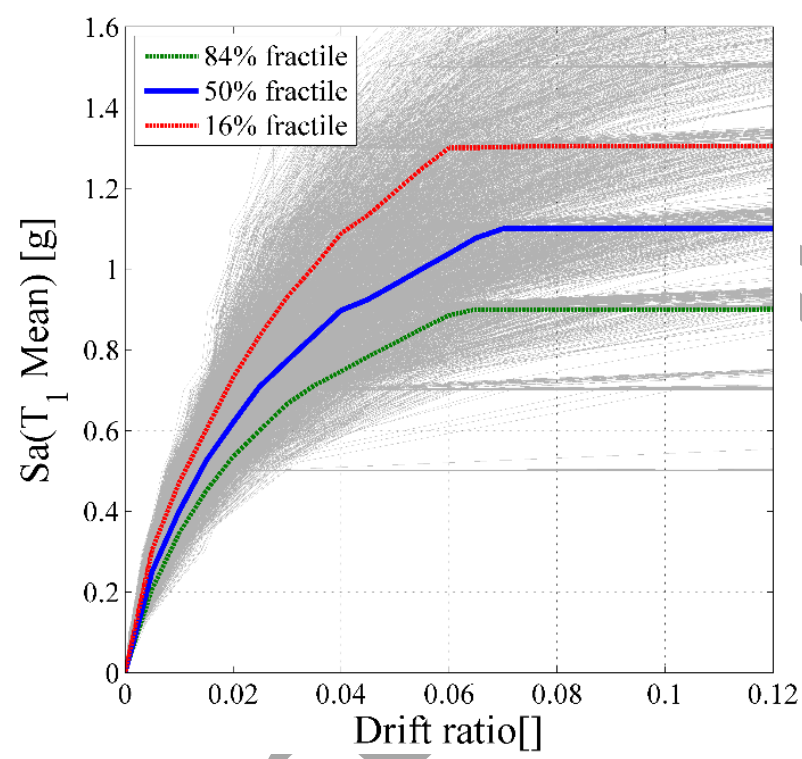

(c)

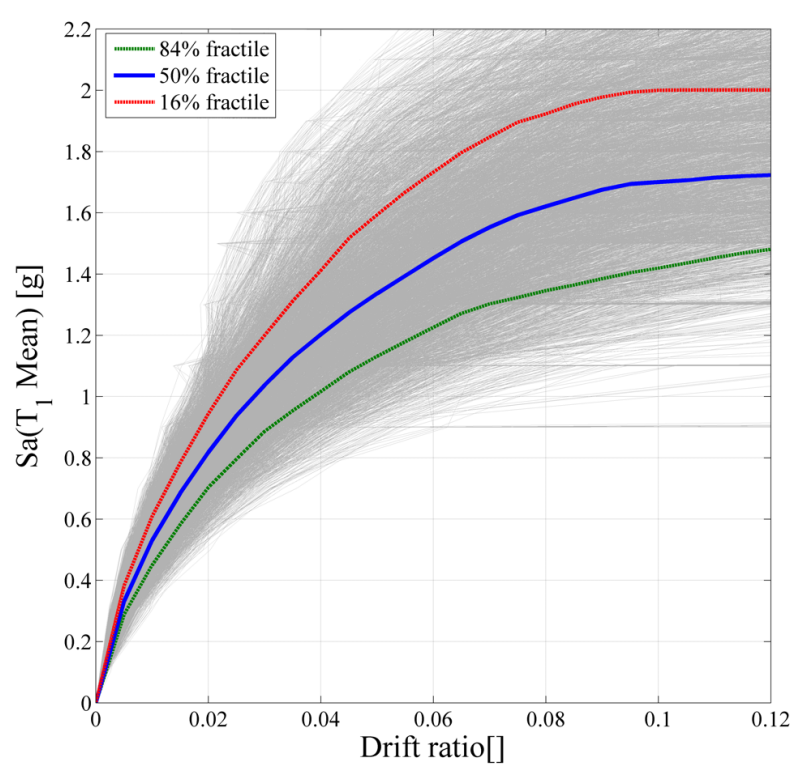

(b)

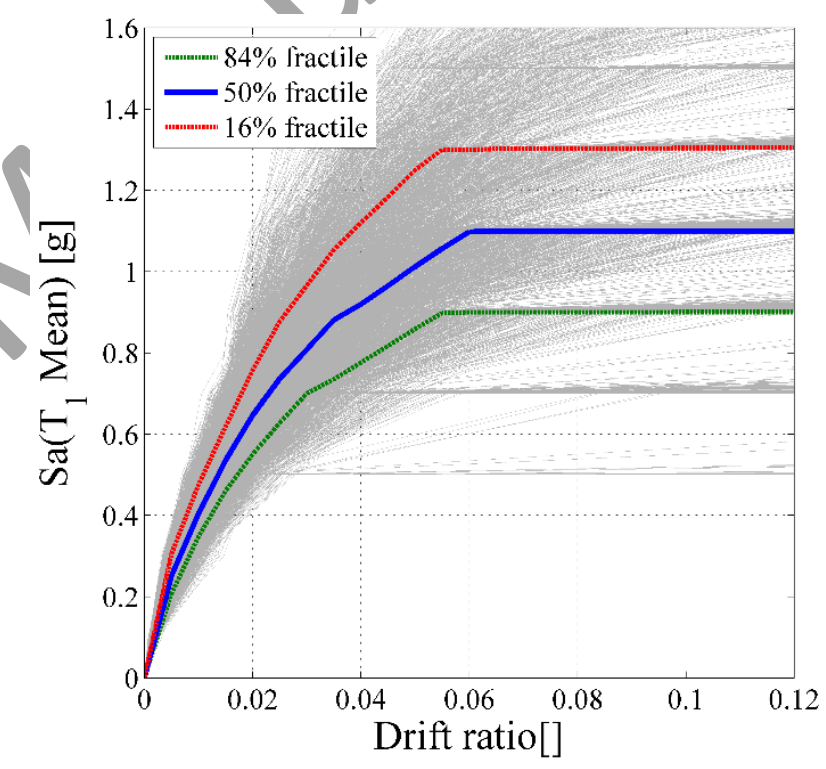

(d)

Fig. 9. IDA graphs: (a) frame A, uncorroded, (b) frame B, uncorroded, (c) frame A, 20\% corroded, and (d) frame B, 20\% corroded 


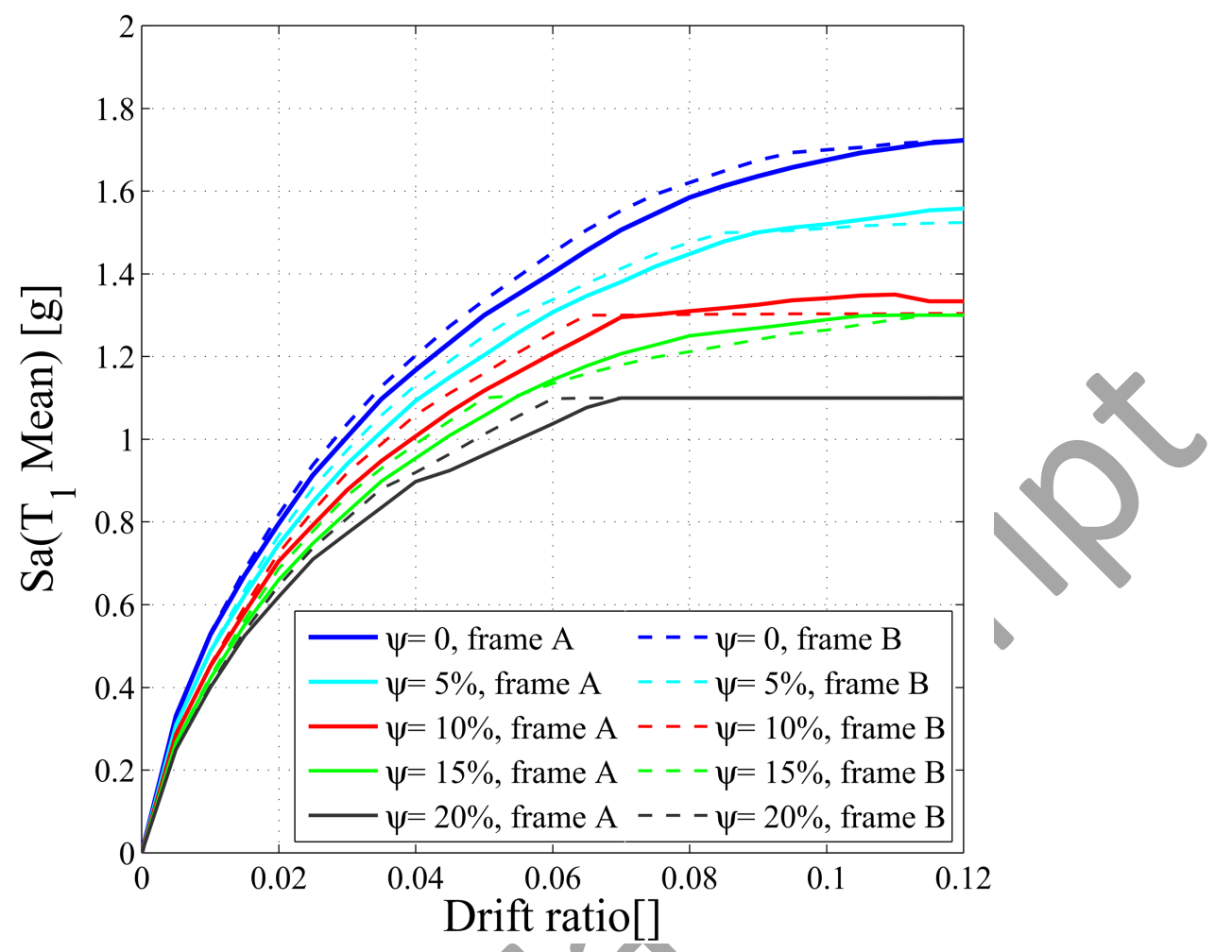

Fig. 10. Median IDA graphs

As can be seen in Fig. 10, median IDA curves of frame A are almost identical with those of frame B. It worth mentioning that all summarized IDA curves in Fig. 10, are median of all 4400 different IDA analyses considering all ground motions and random variables.

To investigate which source of uncertainties affects the results, the influence of record to record variability on nonlinear dynamic behaviour of $20 \%$ corroded frames (Fig. 11) are compared. Fig. 11 shows the median IDA curves of $20 \%$ corroded frames for two example ground motions. As it is shown in Fig. 11 (a), for Kocaeli record the acceleration response of the frame $\mathrm{A}$ is about $30 \%$ higher than frame B. However, for Cape Mendocino record (Fig. 11(b)), there is not any significant difference between the median IDA curves of frame $\mathrm{A}$ and frame $\mathrm{B}$. This shows that the record to record variability significantly affects the nonlinear behaviour of the frames with different confinement levels. It should be noted that the ground motions used in these analyses are all spectrally matched; i.e. the stationary and nonstationary content of ground motions are separated. If ground motions were not spectrally matched, there would have been much more differences in the analyses results. This has been shown in a separate study by Kashani et al. [59]. 


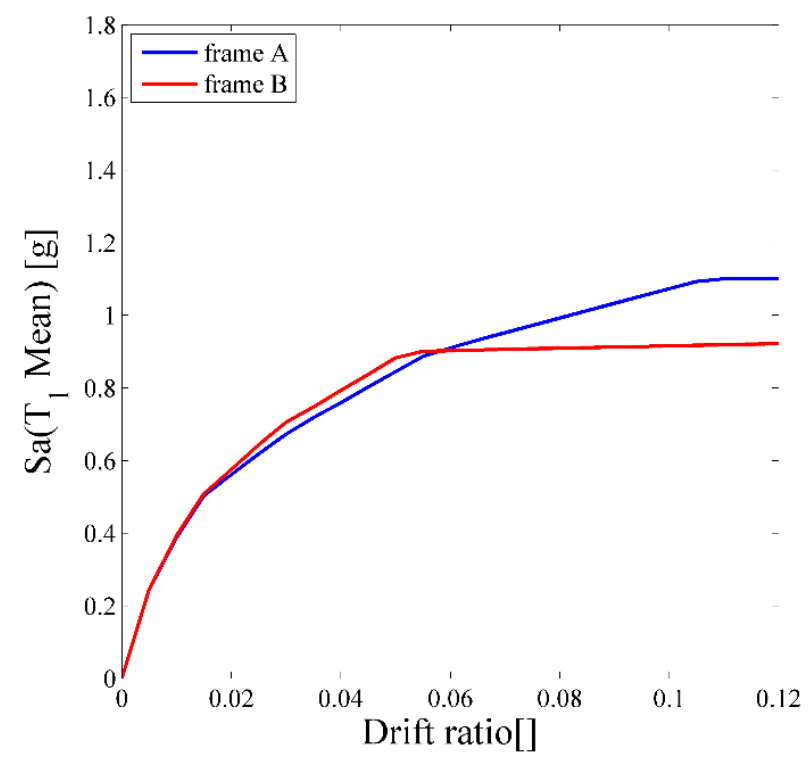

(a)

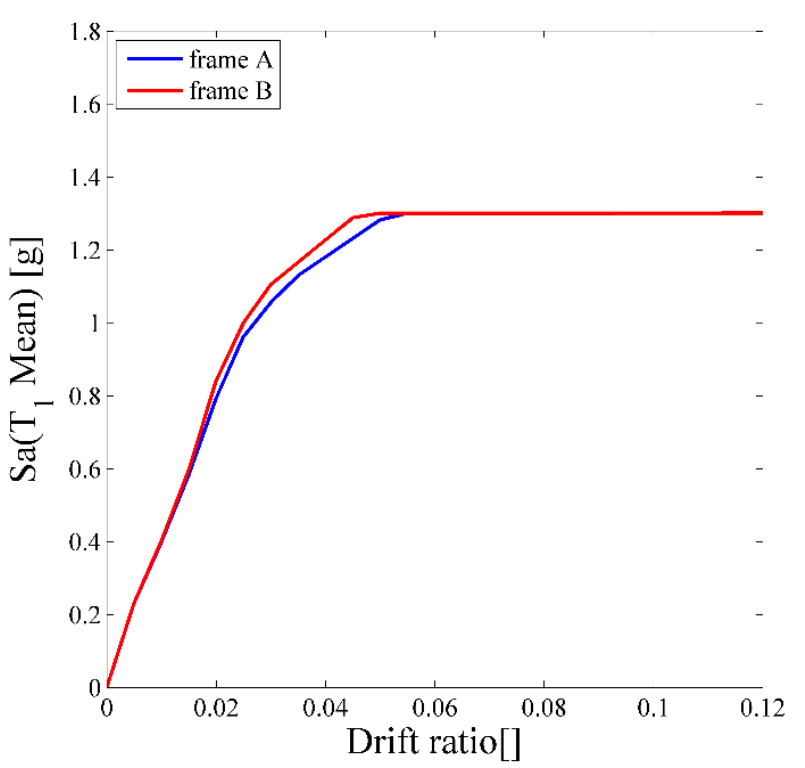

(b)

Fig. 11. Influence of record to record variability on median IDA curves of $20 \%$ corroded frames:

(a) Kocaeli record and (b) Cape Mendocino record

\subsection{Influence of spatial variability of pitting corrosion on nonlinear dynamic} behaviour of corroded $R C$ frames

To explore the effectiveness of considering spatial variation of pitting corrosion on nonlinear dynamic behaviour of the corroded frames, the IDA analyses repeated for $5 \%$ and $20 \%$ corroded frames considering uniform corrosion. Fig. 12 compares median IDA curves for both cases, spatially varied pitting corrosion and uniform corrosion. Figs. 12 shows that for the 5\% corrosion level, the median IDA result of the both frames are approximately same. However, from the Fig. 12 , it is evident that, in $20 \%$ corroded frames, the acceleration response of the model considering uniform corrosion is slightly higher than the model with spatially varied pitting corrosion. The analyses results show that if the spatial variation of pitting corrosion is considered, the structure reaches to complete collapse limit state at approximately 0.06 drift ratio, which is slightly less than the model considering uniform corrosion, which is about 0.08 drift ratio (Fig. 12(a)).

Based on the analyses results, it can be concluded although spatial variability of pitting corrosion might have significant local effect at material level, it may not have a significant impact on the nonlinear dynamic response of the structure globally. This shows that as we scale up our analyses and considering all other uncertainties associated with the model and ground-motions, considering detailed localised corrosion will not have a significant impact on the results (this is further discussed in Section 7.2 of this paper). However, it should be noted that the pitting corrosion distribution models are generally developed using experimental testing by means of accelerated corrosion procedure, and do not include the influence of bar diameters [48]. The real corrosion on site is slightly more non-uniform compare to accelerated corrosion, and different bar diameters, 
the pitting corrosion might be changed [60]. However, there is no experimental and empirical models to account for these parameters. This is an important area for future research.

The only way that localised pitting corrosion might have a significant impact on the global response is that the structure suffers from a severe localised pitting corrosion at a critical location (plastic hinge), which is not something we can directly predict. This can happen due to defects and surface cracks in the cover concrete and/or quality of construction.

It should be noted that in Eqs. (3) and (4), residual capacity and ductility, as well as inelastic buckling and low-cycle fatigue of corroded bars are included in the reinforcing steel model, which account for the effects of pitting corrosion [3,4]. Therefore, the monotonic pushover analysis is not purely based on the uniform corrosion of reinforcements as the modified material models account for the impact of pitting corrosion. However, these models assume that the pitting corrosion is not spatially distributed along the length of the structural components.

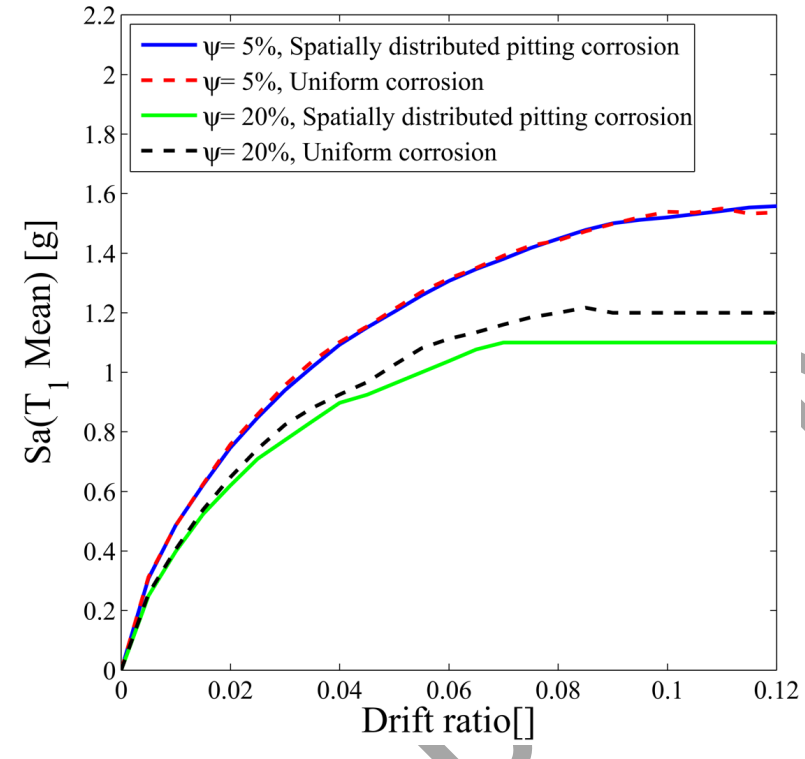

(a)

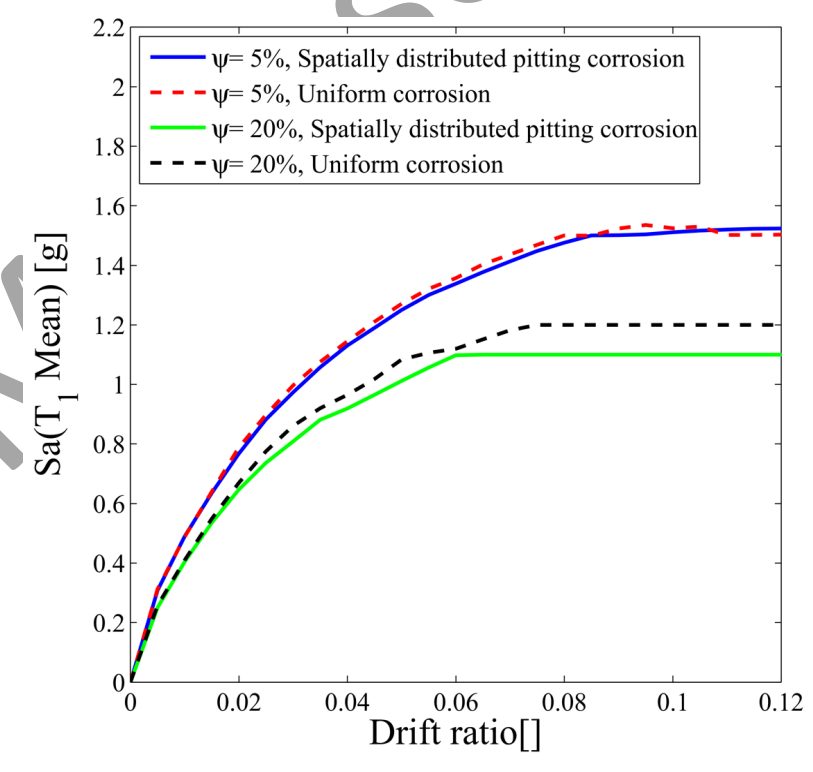

(b)

Fig. 12. Influence of considering spatial variability of pitting corrosion on IDA results of corroded frames: a) frame A; b) frame B

\section{Influence of corrosion on seismic vulnerability of the RC frames}

Fragility curves are commonly used to quantitatively assess the seismic vulnerability of structures to earthquakes. In these curves the probability of exceedance from a specific damage index is generally described in terms of an intensity measure of earthquakes. The fragility function is generally determined using the cumulative log-normal distribution function according to Eq.(11) [61]: 


$$
\int P\left[S D L \geq D M \mid S a\left(T_{1}\right)=y\right]=\Phi\left(\frac{\ln (\mathrm{y})-\mu_{l n}}{\sigma_{l n}}\right)
$$

Where $D M$ denotes the considered damage limit state, $y$ denotes the value of first mode spectral acceleration that cause structure reach to the $D M, \Phi($.$) is the lognormal distribution function with$ mean of $\mu_{l n}$ (Eq.(12)) and standard deviation of $\sigma_{\ln }$ (Eq.(13)):

$$
\begin{aligned}
& \mu_{\mathrm{ln}}=\frac{1}{n} \sum_{i=1}^{n} \ln \left(\operatorname{Sa}\left(T_{1}\right)_{i}\right) \\
& \sigma_{\mathrm{ln}}=\frac{1}{n-1} \sqrt{\sum_{i=1}^{n}\left[\ln \left(\operatorname{Sa}\left(T_{1}\right)_{i}\right)-\mu_{\mathrm{ln}}\right]^{2}}
\end{aligned}
$$

Where $n$ is the number of each individual IDAs (is this study $n=4400$ ) and $\mathrm{Sa}\left(\mathrm{T}_{1}\right)_{\mathrm{i}}$ is the spectral acceleration corresponding to onset of a specific SDL.

\subsection{Fragility curves of corroded RC frames considering time-variant SDLS}

In this part, fragility curves are plotted using time-variant SDLS obtained from monotonic pushover analysis in section 5 of this paper. Furthermore, to show the importance of considering time-variant SDLS, fragility curves are also plotted based on the damage limit states of uncorroded structures according to HAZUS-MH MR5 [57] for moment-resisting RC frames.

Fig. 13 shows the fragility curves of complete damage state. As it is shown in Fig. 13, as percentage of mass loss increases the probability of exceedance of complete damage state significantly increases. For instance, according to Fig. 13 (a), while probability of exceedance from $\mathrm{Sa}=1.6 \mathrm{~g}$ is approximately $50 \%$ for uncorroded frame, it is $100 \%$ for $20 \%$ corroded frame. On the other hand, from the Fig. 13(b) and 13(c), the probability of failure is underestimated using time-invariant SDLS proposed in HAZUS-MH MR5 [57]. For example, using time-variant SDLS probability of exceedance from $\mathrm{Sa}=1 \mathrm{~g}$ is $90 \%$ for $20 \%$ corroded frame in Fig. 13(a). However, it is just under $35 \%$ using the time-invariant SDLS in Fig. 13(b).

The fragility curves for extensive damage limit state (corresponding to occurrence of cover spalling) are shown in Fig. 14. From the Fig. 14(a) and 14(b), it is evident that probability of occurrence of cover spalling increases significantly as corrosion level increases. For example, according to Fig. 14(a), the probability of exceedance of extensive damage limit state of uncorroded frame for $\mathrm{Sa}=1.2 \mathrm{~g}$ is less than $10 \%$, and it is approximately $100 \%$ for all the corroded frames. However, like Fig. 14, using time-invariant extensive damage limit state, the probability of occurrence of cover spalling will be underestimated in corroded frames. 


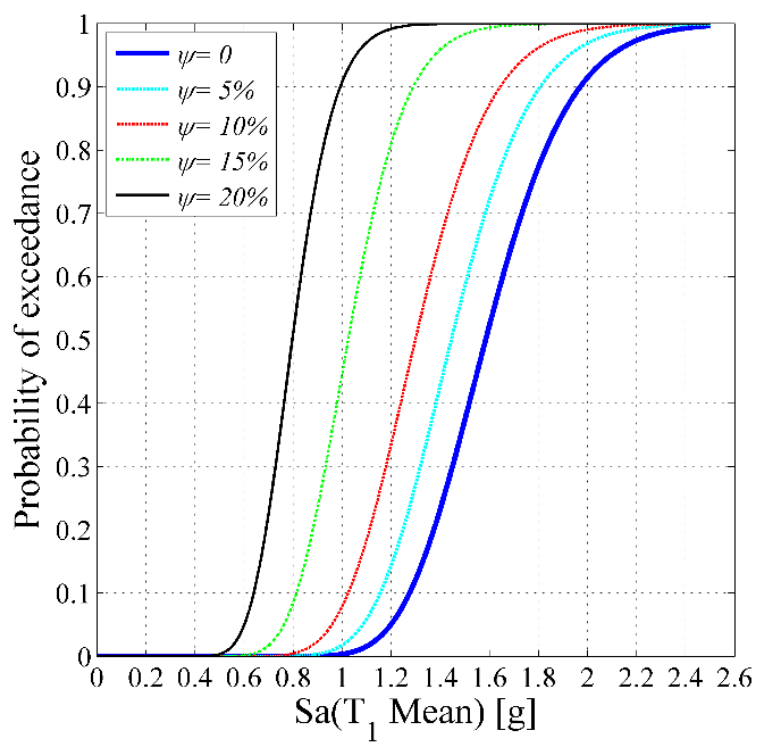

(a)

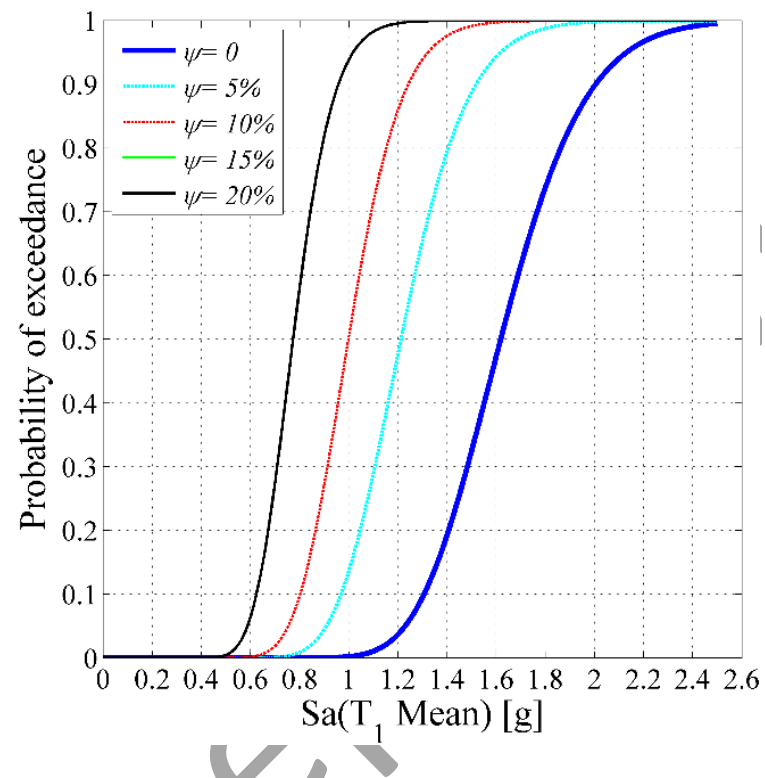

(c)

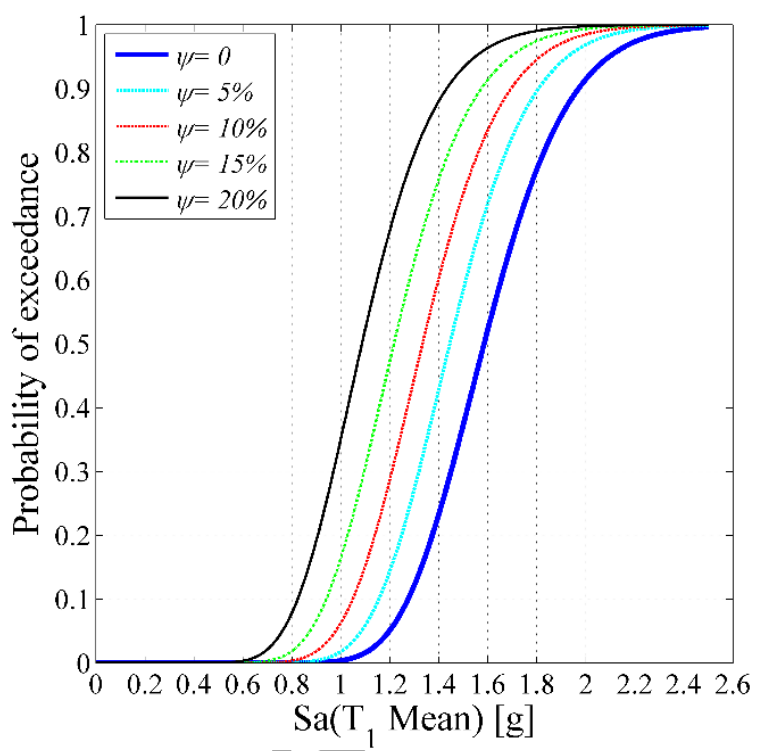

(b)

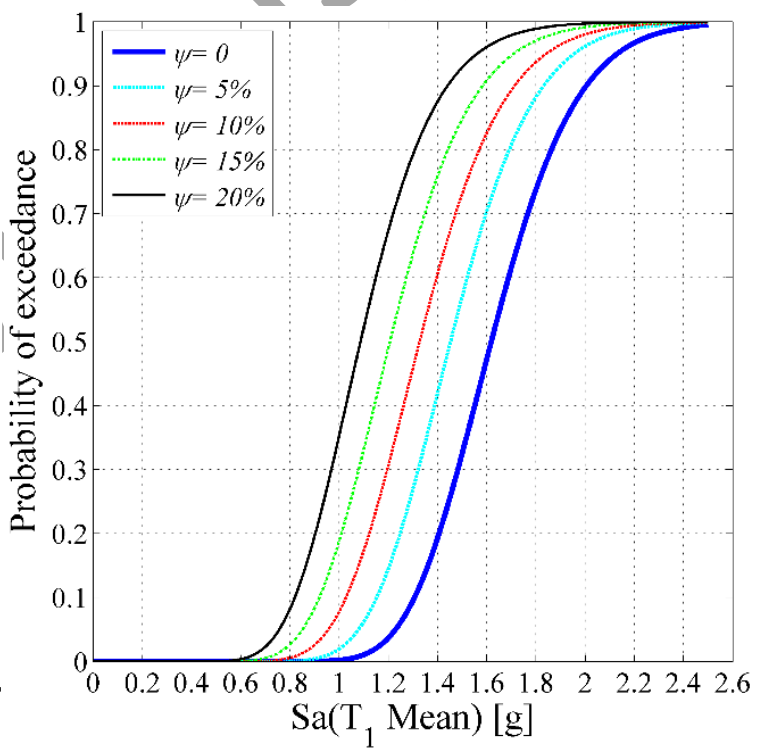

(d)

Fig. 13. Complete SDLS fragility curves for frames A and B: (a) time-variant SDLS frame A, (b) time-invariant SDLS frame A, (c) time-variant SDLS frame B, and (d) time-invariant SDLS frame B 


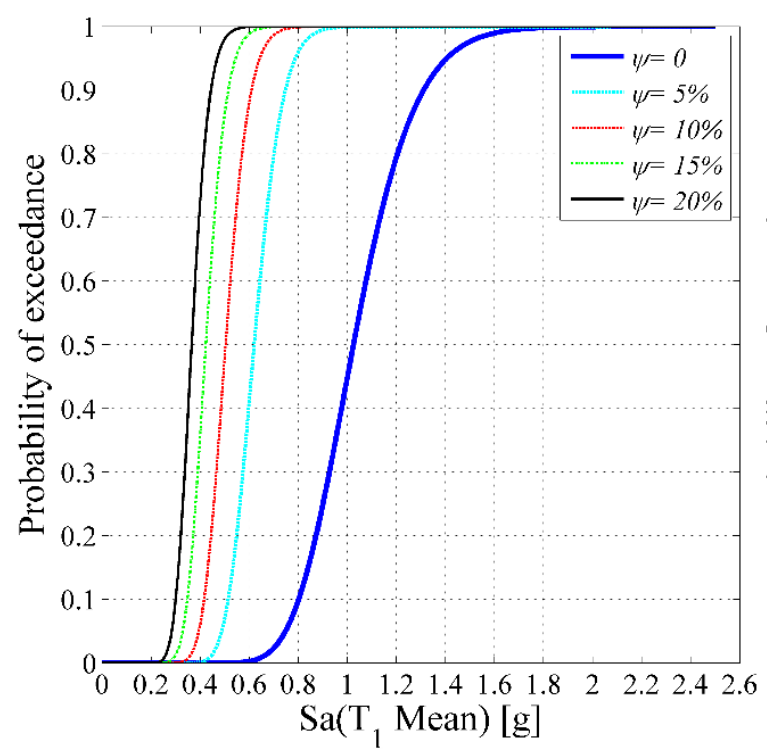

(a)

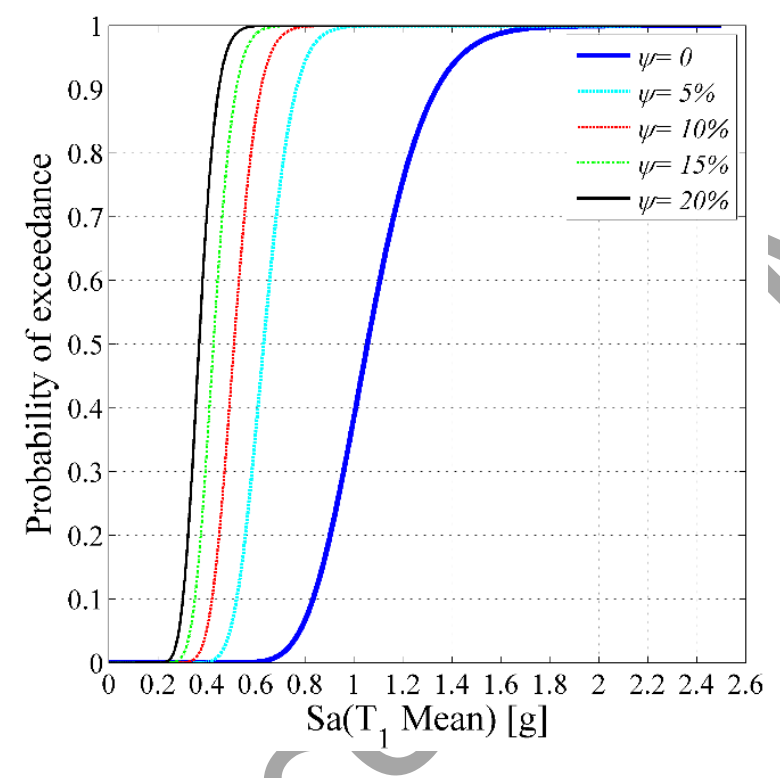

(c)

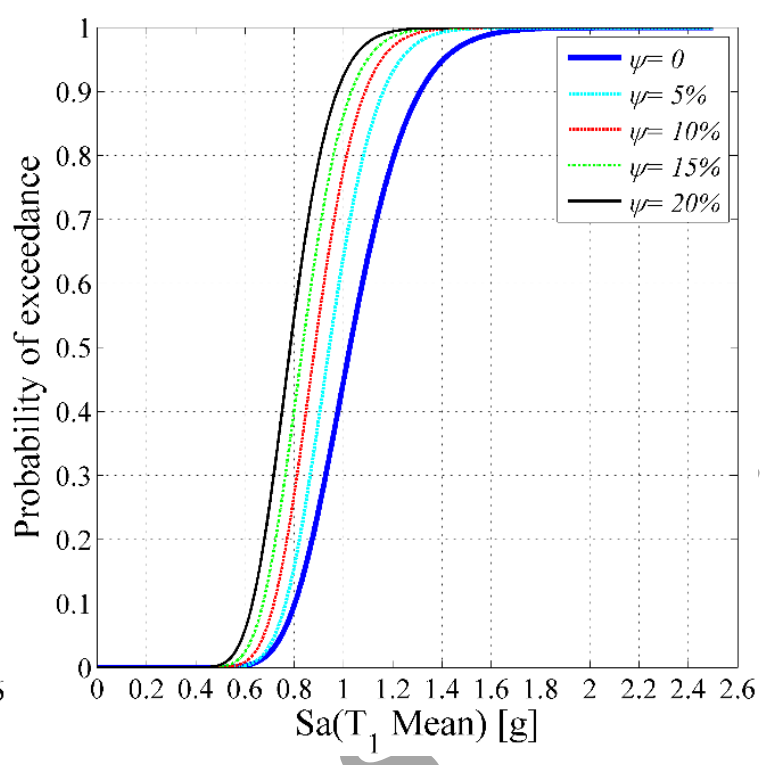

(b)

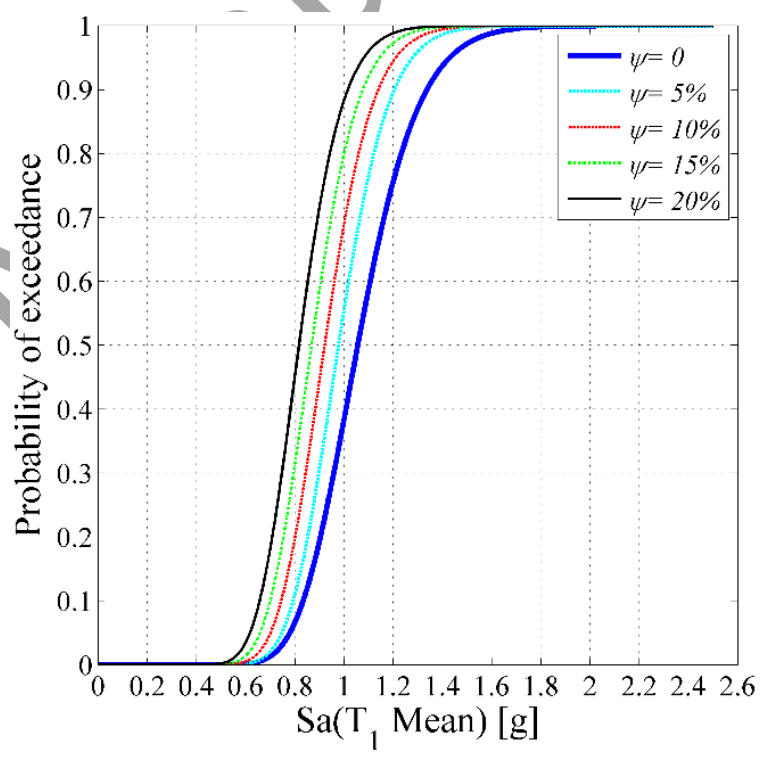

(d)

Fig. 14. Extensive SDLS fragility curves for frames A and B: (a) time-variant SDLS frame A, (b) time-invariant SDLS frame A, (c) time-variant SDLS frame B, and (d) time-invariant SDLS frame B

\subsection{Influence of spatial variability of pitting corrosion on seismic vulnerability of corroded frames}

In this part the influence of considering spatial variability of pitting corrosion on seismic fragility curves is investigated. To this end, as an example, fragility curve of complete damage limit state of $20 \%$ corroded frames are plotted with and without considering the spatial variability of pitting 
corrosion. As it is shown in Fig. 15, the probability of exceedance from a specific spectral acceleration is underestimated considering uniform corrosion. For example, Fig. 15(a) shows that while considering the spatial variability of pitting corrosion the probability of exceeding of frame A from $\mathrm{Sa}=0.8 \mathrm{~g}$ is approximately $48 \%$, it is $35 \%$ considering uniform corrosion. Similarly, Fig. 15 (b) shows that considering spatial variability of pitting corrosion does not a significant effect on the probability of failure of frame B. For example, probability of exceeding of frame B from $\mathrm{Sa}=0.8 \mathrm{~g}$ is approximately $55 \%$ and $45 \%$ considering spatially distributed pitting corrosion and uniform corrosion, respectively. However, as explained earlier in the paper, the impact of spatially varied pitting corrosion on seismic vulnerability of corroded frames in comparison to other sources of uncertainties (model uncertainties and ground motions) is negligible.

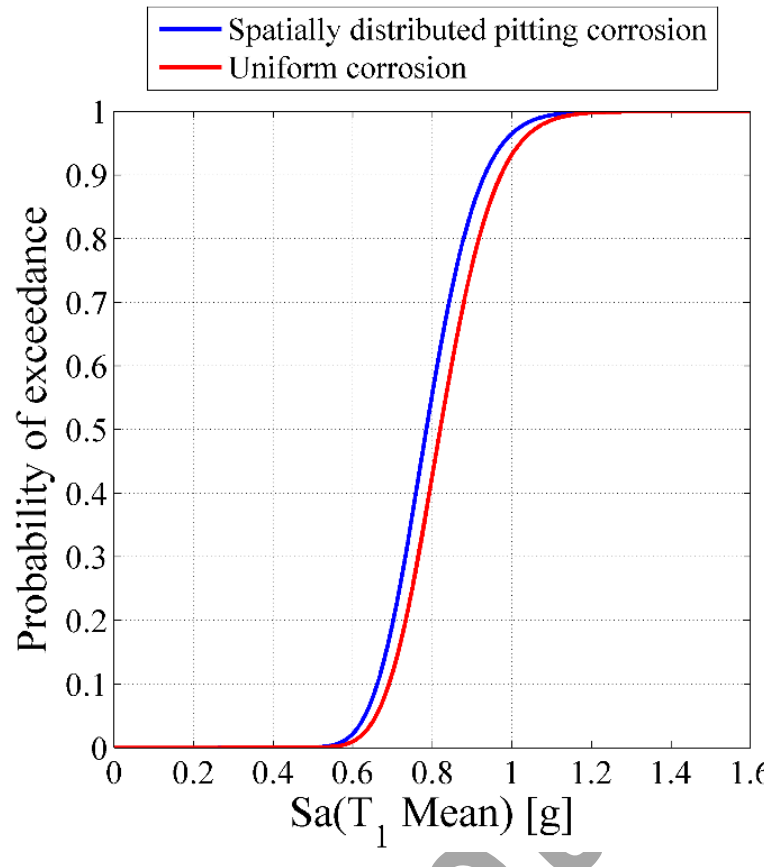

(a)

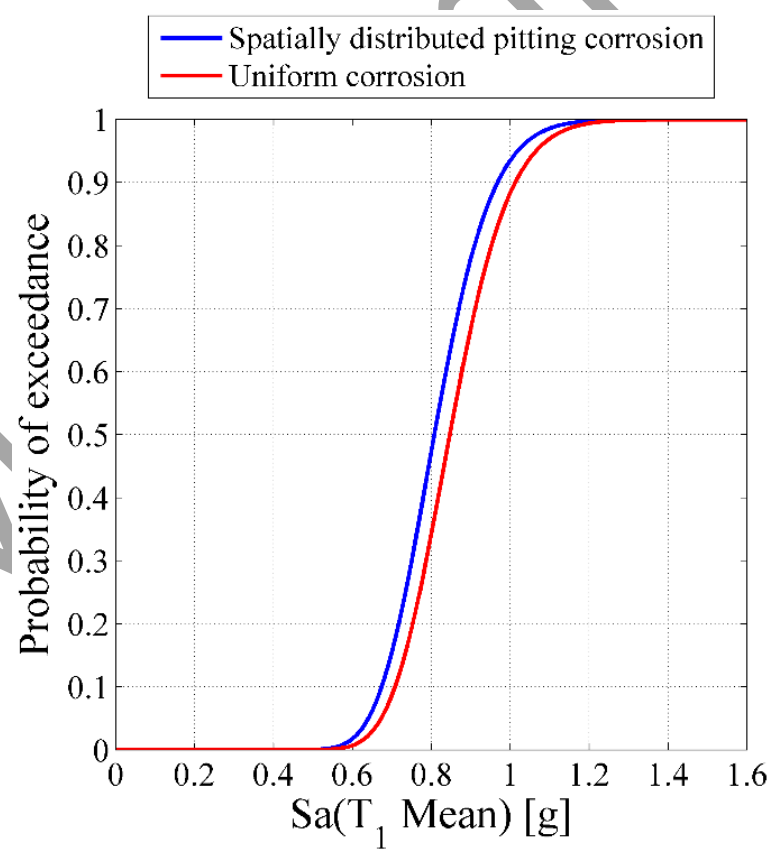

(b)

Fig. 15. Influence of considering spatial variability of pitting corrosion on fragility curves of 20\% corroded frames: a) Frame A; b) Frame B

\section{Adequacy of proposed damage limit states in material scale}

Fig. 16 shows the maximum normalised strain in longitudinal reinforcement and core concrete of the right column of uncorroded RC frames for all the 4400 analyses cases. The normalised reinforcement strain is the maximum tensile strain of reinforcements in each IDA normalised to the fracture strain of the corroded reinforcement. Similarly, the normalised strain of the core concrete is the maximum strain of the core concrete in each IDA normalised to the crushing strain of the corrosion damaged core concrete.

As is it shown in Fig. 16(a) and (c), for the well confined uncorroded frame A, the maximum normalised strains of reinforcement and core concrete are all below 1.0. However, Fig. 16 (d) 
shows that beyond the associated drift of complete damage, which is 0.075 (Table 4), in several combinations normalised core concrete crushing strain reaches 1.0. This shows that, there is a good correlation between the global damage limit states proposed in HAZUS-MH MR5 [57] and local material damage for uncorroded RC structures. It should be noted that HAZUS-MH MR5 [57] considers the inter-storey drift ratio of 0.08 as the complete damage threshold for high-code low-rise RC frames.

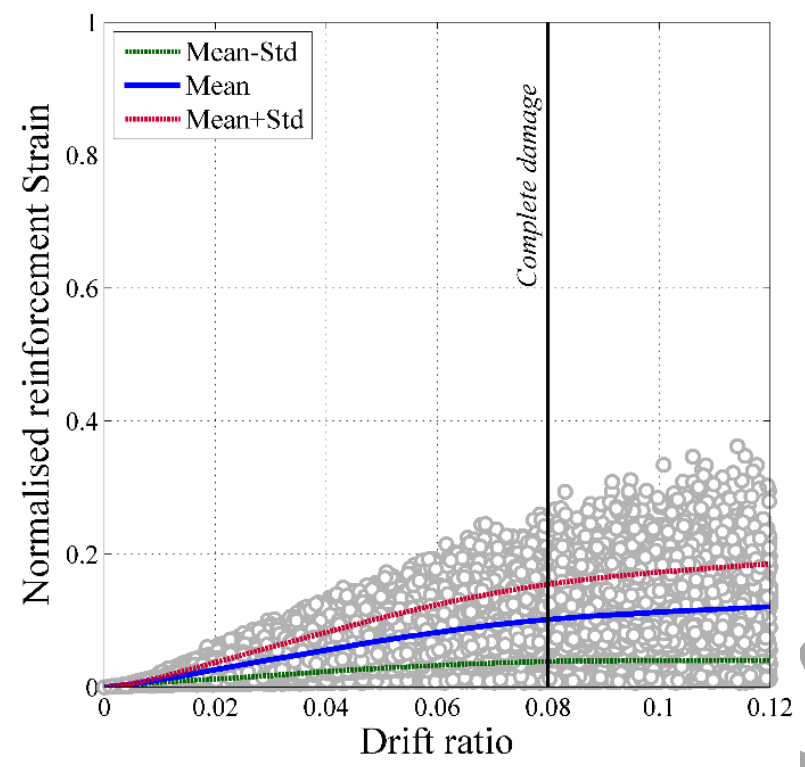

(a)

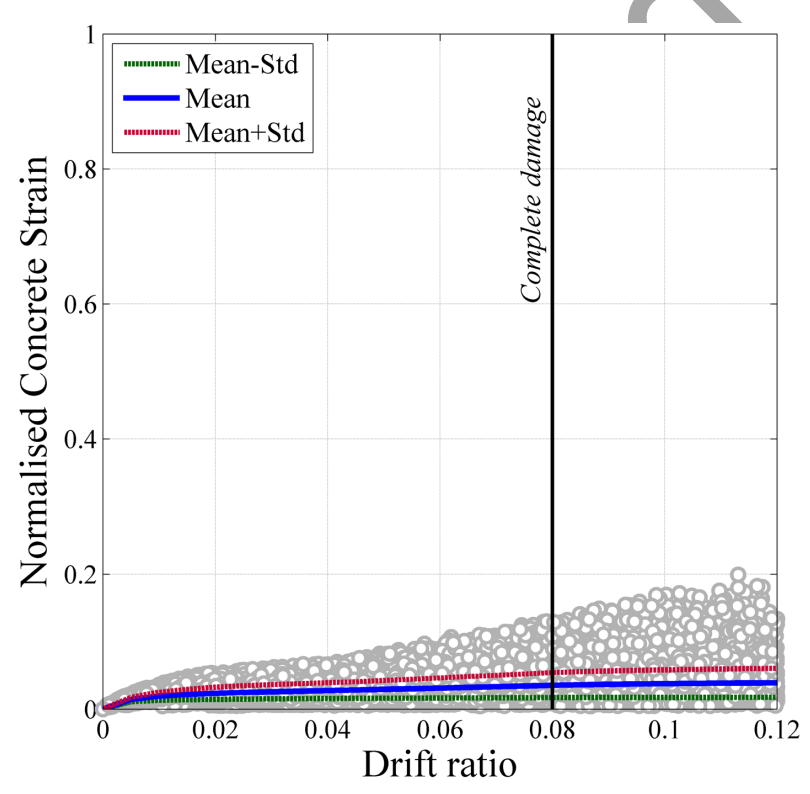

(c)

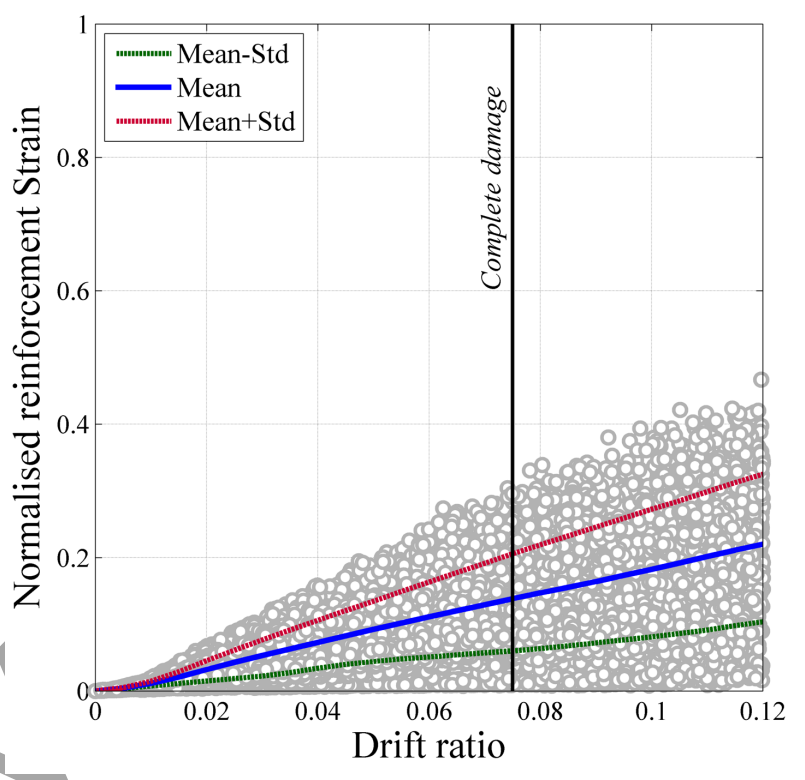

(b)

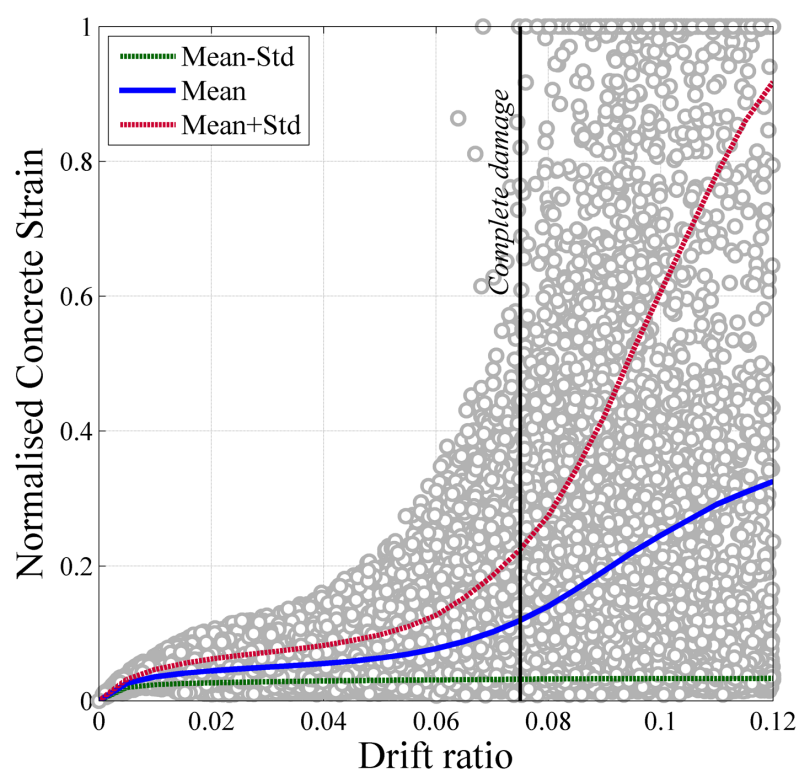

(d)

Fig. 16. Distribution of normalised reinforcement strain and normalised core concrete strain in critical section of uncorroded frames: (a) and (c) Frame A; (b) and (d) Frame B. 
Fig. 17 shows the normalised material strains for $20 \%$ corroded RC frames. Both of time-variant and time-invariant complete damage limit state margins are also shown in Fig. 17.

As it is shown in Fig. 17, the normalised strains of the materials are very scattered. This is because the nonlinear behaviour of the corroded frames is significantly dependent on the random variables.

As shown in Figs. 17(d), in most of the cases the core concrete crushing is occurred from approximately $0.02 \mathrm{drift}$ ratio. This is well described by time-variant complete damage limit state which is at $0.027 \mathrm{drift}$ ratio (Table 4). However, it is evident that the time-invariant damage limit state is significantly underestimates the collapse of the structure at material level. A similar trend can be seen in Fig. 17(b), where in several cases the bar fracture occurs before the margin of timeinvariant collapse damage limit state.

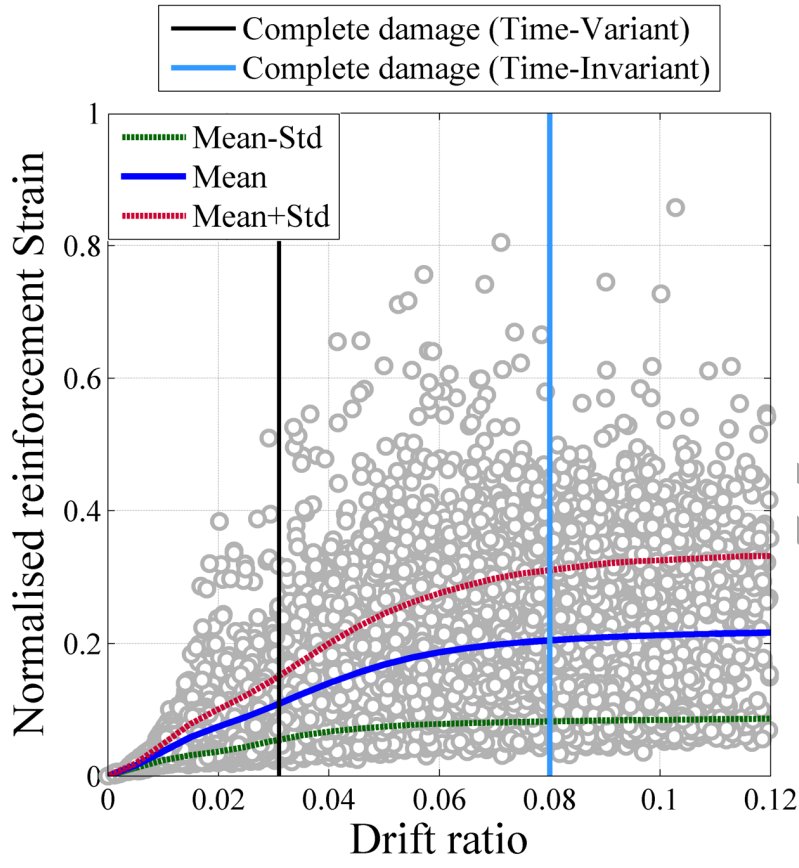

(a)

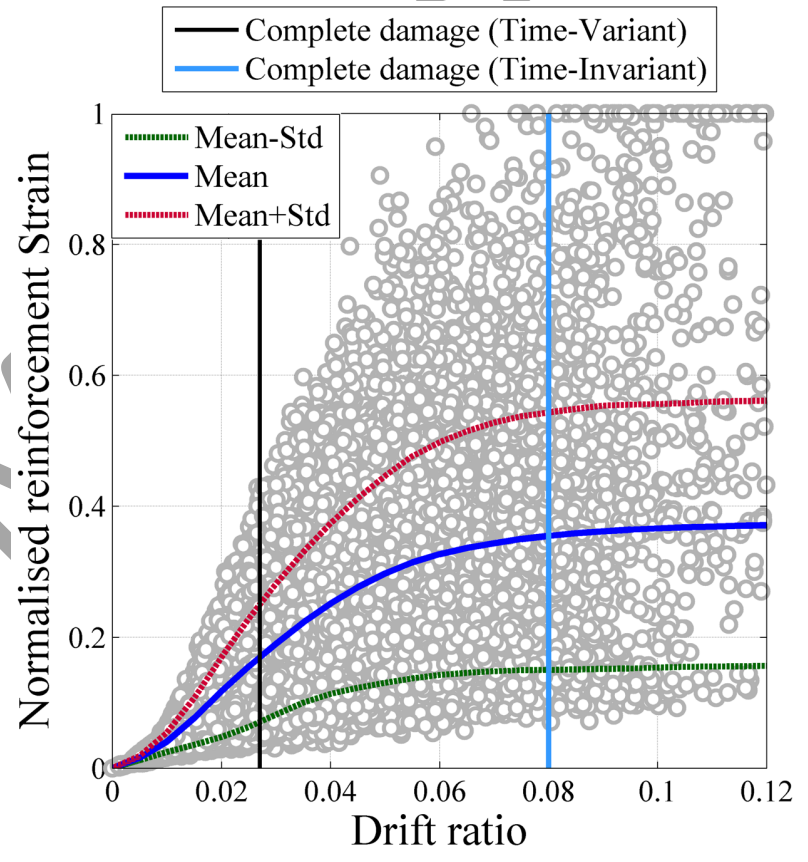

(b) 


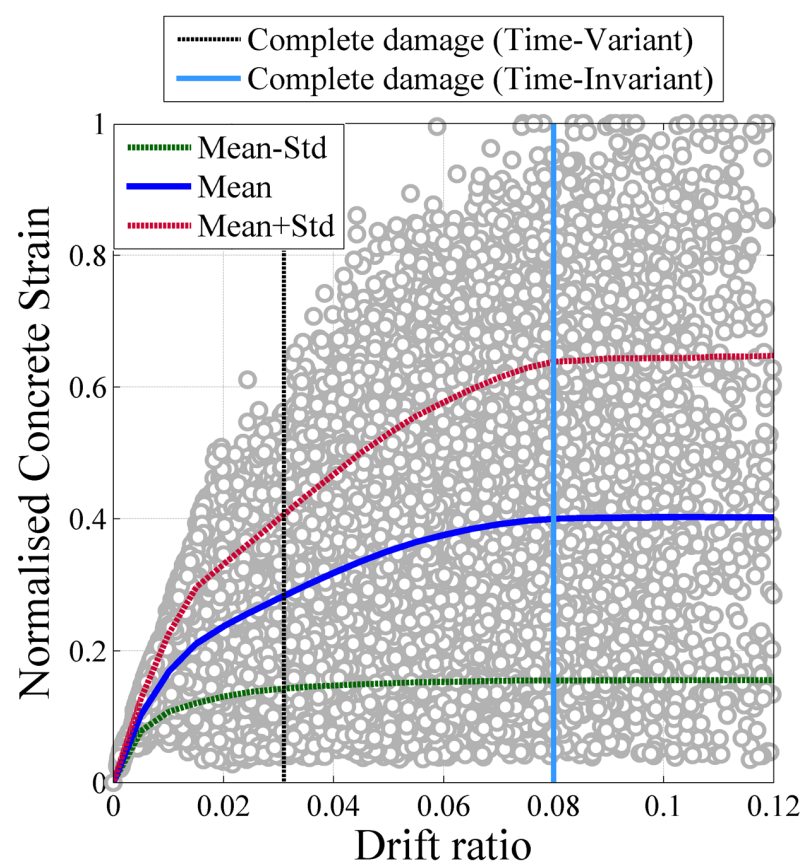

(c)

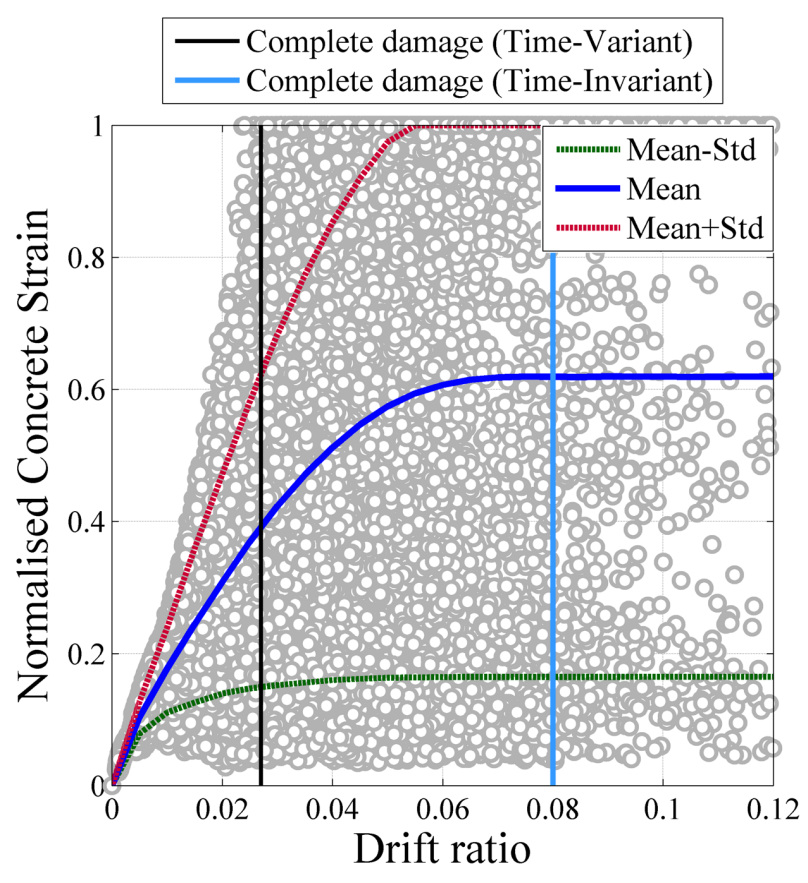

(d)

Fig. 17. Distribution of normalised reinforcement strain and normalised core concrete strain in critical section of 20\% corroded frames: (a) and (c) Frame A; (b) and (d) Frame B.

\section{Summary and Conclusions}

Two RC frames with different reinforcing details are designed to represent the code conforming and code nonconforming structures. The RC members of the proposed frames are considered to be fully exposed to chloride attack. The previously verified modelling technique of corroded rectangular RC columns [16] is extended to create the NFEM of corroded RC frames with different corrosion levels. Using LHS, hundred NFEMs generated considering uncertainties in geometrical dimensions, material properties and spatial variability of pitting corrosion. The time-yariant SDLS are defined for each frame by conducting a series of monotonic pushover analyses.

The influence of corrosion on nonlinear dynamic behaviour of corroded RC frames is evaluated through IDA using spectrally matched far-field ground motions. It was shown that maximum acceleration response of corroded frames is significantly reduced in comparison with that of uncorroded frames. It was also shown that ignoring spatial variability of pitting corrosion results in a slight overestimation of structural capacity. However, it is concluded that in modelling nonlinear behaviour, considering uniform corrosion, and including the pitting corrosion by means of amending yield strength, ductility, inelastic buckling, low-cycle fatigue life, and confinement is sufficient. 
Using the IDA results, time-dependent fragility curves are developed for each frame considering both time-variant and time-invariant SDLS. Comparison of results indicates that disregarding time-variant SDLS, significantly underestimates the probability of failure of corroded structures. Furthermore, ignoring the spatial distribution of pitting corrosion in the analyses underestimates the probability of exceedance from a specific SDLS. Therefore, it is crucial to consider the time-variant SDLS in seismic fragility analysis and reliability assessments of corroded RC structures.

\section{References}

1. Chiu C.K, Tu F.J, Hsiao F.P. Lifetime seismic performance assessment for chloride-corroded reinforced concrete buildings. Structure and Infrastructure Engineering, 2015;11(3): 345-362.

2. Gaal G.C.M. Prediction of deterioration of concrete bridges. PhD thesis, TU Delft, 2004.

3. Du Y, Clark L, Chan A. Effect of corrosion on ductility of reinforcing bars. Magazine of Concrete Research, 2005; 57(7): 407-419.

4. Du Y, Clark L, Chan A. Residual capacity of corroded reinforcing bars. Magazine of Concrete Research, 2005; 57(3): 135-147.

5. Lee H.S, Noguchi T, Tomosawa F. Evaluation of the bond properties between concrete and reinforcement as a function of the degree of reinforcement corrosion. Cement and Concrete research, 2002.; 32(8): 1313-1318.

6. Fang C, Lundgren K, Plos M, Gylltoft K. Bond behaviour of corroded reinforcing steel bars in concrete. Cement and concrete research, 2006; 36(10): 1931-1938.

7. Williamson S, Clark L. Pressure required to cause cover cracking of concrete due to reinforcement corrosion. Magazine of Concrete research, 2000; 52(6): 455-467.

8. Kashani M. M, Alagheband P, Khan R, Davis S. Impact of corrosion on low-cycle fatigue degradation of reinforcing bars with the effect of inelastic buckling. International Journal of Fatigue, 2015; 77: 174-185.

9. Meda A, Mostosi S, Rinaldi Z, Riva P. Experimental evaluation of the corrosion influence on the cyclic behaviour of RC columns. Engineering Structures, 2014; 76: 112-123.

10. Guo A, Li H, Ba X, Guan X, Li H. Experimental investigation on the cyclic performance of reinforced concrete piers with chloride-induced corrosion in marine environment. Engineering Structures, 2015; 105: 1-11.

11. Ma Y, Che Y, Gong J. Behavior of corrosion damaged circular reinforced concrete columns under cyclic loading. Construction and Building Materials, 2012; 29: 548-556.

12. Ou Y.C, Tsai L.L, Chen H.H. Cyclic performance of large-scale corroded reinforced concrete beams. Earthquake Engineering \& Structural Dynamics, 2012; 41(4): 593-604. 
13. Alipour A, Shafei B, Shinozuka M. Performance evaluation of deteriorating highway bridges located in high seismic areas. Journal of Bridge Engineering, 2011;6: 597-611

14. Rao A.S, Lepech M.D, Kiremidjian A.S, Sun X.Y. Simplified structural deterioration model for reinforced concrete bridge piers under cyclic loading. Structure and Infrastructure Engineering, 2016: 1-12.

15. Titi A. Lifetime probabilistic seismic assessment of multistory precast buildings. Ph.D thesis, Polytechnic University of Milan, Italy, 2012.

16. Afsar Dizaj E, Madandoust R, Kashani M.M. Exploring the impact of chloride-induced corrosion on seismic damage limit states and residual capacity of reinforced concrete structures. Structure and Infrastructure Engineering, 2018, 14(6): 714-729.

17. Ghosh J, Sood P. Consideration of Time-Evolving Capacity Distributions and Improved Degradation Models for Seismic Fragility Assessment of Aging Highway Bridges. Reliability Engineering \& System Safety, 2016; $154: 197-218$.

18. Stewart M.G, Sue Q. Extent of spatially variable corrosion damage as an indicator of strength and time-dependent reliability of RC beams. Engineering Structures, 2009; 31(1): 198-207.

19. Ni Choine, M. Seismic Reliability Assessment of Aging Integral Bridges. University of Dublin, Ph.D thesis, 2014.

20. Choe D-E, Gardoni P, Rosowsky D, Haukaas T. Probabilistic capacity models and seismic fragility estimates for RC columns subject to corrosion. Reliability Engineering \& System Safety, 2008; 93(3): 383-393.

21. Guo A, Yuan W, Lan Ch, Guan X, Li H. Time-dependent seismic demand and fragility of deteriorating bridges for their residual service life. Bulletin of Earthquake Engineering, 2015: 1-2

22. Ni Choine M, Kashani M. M, Lowes L.N, O'Connor A, Crewe A.J, Alexander N.A. Nonlinear dynamic analysis and seismic fragility assessment of a corrosion damaged integral bridge. International Journal of Structural Integrity, 2016;7(2): 227-239.

23. Lim, S., M. Akiyama, and D.M. Frangopol, Assessment of the structural performance of corrosion-affected RC members based on experimental study and probabilistic modeling. Engineering Structures, 2016. 127: p. 189-205.

24. Kioumarsi M.M, Hendriks M, Kohler J, Geiker M. The effect of interference of corrosion pits on the failure probability of a reinforced concrete beam. Engineering Structures, 2016; 114: 113121.

25. Vamvatsikos D, Cornell C.A. Incremental dynamic analysis. Earthquake Engineering and Structural Dynamics, 2002; 31(3): 491-514.

26. FEMA P695, Quantification of Building Seismic Performance Factors. Federal Emergency Management Agency, Washington, DC; 2009. 
27. Helton J.C, Davis F.J. Latin hypercube sampling and the propagation of uncertainty in analyses of complex systems. Reliability Engineering and System Safety, 2003; 81(1): 23-69.

28. BHRC, Iranian code of practice for seismic resistant design of buildings, Standard No. 2800, Building and Housing Research Center, Tehran, Iran. 2005.

29. ASCE-7. Minimum design loads for buildings and other structures. Structural Engineering Institute. 2002.

30. ACI. Building code requirements for structural concrete." ACI 318-02, American Concrete Institute,Farmington Hills. 2002.

31. Spacone E, Filippou F, Taucer F.F. Fibre beam-column model for non-linear analysis of R/C frames: Part I. Formulation. Earthquake engineering and structural dynamics, 1996; 25(7): 711726.

32. McKenna F. OpenSees: a framework for earthquake engineering simulation. Computing in Science \& Engineering, 2011; 13(4): 58-66.

33. Stefanou G, Fragiadakis M. Nonlinear dynamic analysis of frames with stochastic nonGaussian material properties. Engineering structures, 2009 (31):1841-1850.

34. Berry M.P, Eberhard M.O. Performance modeling strategies for modern reinforced concrete bridge columns, Pacific Earthquake Engineering Research Center, University of California, Berkeley,2007.

35. Kashani M.M, Lowes L, Crewe A.J, Alexander N.A. Phenomenological hysteretic model for corroded reinforcing bars including inelastic buckling and low-cycle fatigue degradation. Computers \& Structures, 2015; 156:58-71.

36. Dhakal R.P, Maekawa K. Reinforcement stability and fracture of cover concrete in reinforced concrete members. Journal of Structural Engineering, 2002; 128(10), 1253-1262.

37. Kashani M.M, Lowes L, Crewe A.J, Alexander N.A. Computational modelling strategies for nonlinear response prediction of corroded circular RC bridge piers. Advances in Materials Science and Engineering, 2016, http://dx.doi.org/10.1155/2016/2738265.

38. Dolsek $\mathrm{M}$. Ineremental dynamic analysis with consideration of modeling uncertainties. Earthquake Engng Struct. Dyn. 2009; 38:805-825.

39. Vamvatsikos D, Fragiadakis M. Incremental dynamic analysis for estimating seismic performance sensitivity and uncertainty, Earthquake Engng Struct. Dyn. 2010; 39:141-163.

40. Fang JQ, Li QS, Jeary AP, Liu DK. Damping of tall buildings: its evaluation and probabilistic characteristics. The structural design of tall buildings, 1999 (8): 145-153.

41. Val D.V, Chernin L. Serviceability reliability of reinforced concrete beams with corroded reinforcement. Journal of structural engineering, 2009; 135(8): 896-905.

42. Melchers R.E. Structural reliability analysis and prediction. John Wiley \& Son Ltd, 1999. 
43. Val D.V. Factors affecting life-cycle cost analysis of RC structures in chloride contaminated environments. Journal of infrastructure systems, 2007; 13(2): 135-143.

44. Enright M.P, Frangopol D.M. Probabilistic analysis of resistance degradation of reinforced concrete bridge beams under corrosion. Engineering structures, 1998; 20(11): 960-971.

45. Kappos A, Chryssanthopoulos M, Dymiotis C. Uncertainty analysis of strength and ductility of confined reinforced concrete members. Engineering structures, 1999; 21(3): 195-208.

46. Darmawan M. Pitting corrosion model for reinforced concrete structures in a chloride environment. Magazine of Concrete Research, 2010; 62(2): 91-101.

47. Stewart M.G. Spatial variability of pitting corrosion and its influence on structural fragility and reliability of RC beams in flexure. Structural Safety, 2004; 26(4): 453-470.

48. Kashani M.M, Crewe A.J, Alexander N.A. Use of a 3D optical measurement technique for stochastic corrosion pattern analysis of reinforcing bars subjected to accelerated corrosion. Corrosion Science, 2013; 73: 208-221.

49. Coronelli D, Gambarova P. Structural assessment of corroded reinforced concrete beams: modeling guidelines. Journal of Structural Engineering, 2004; 130(8): 1214-1224.

50. Scott B, Park R, Priestley M. Stress-strain behavior of concrete confined by overlapping hoops at low and high strain rates. ACI Journal, 1982: 13-27.

51. Kashani M.M. Seismic Performance of Corroded RC Bridge Piers: Development of a MultiMechanical Nonlinear Fibre Beam-Column Model. PhD Thesis, University of Bristol, 2014.

52. Zhao J, Sritharan S. Modeling of strain penetration effects in fiber-based analysis of reinforced concrete structures. ACI structural journal, 2007. 104(2): 133-141.

53. Mergos P.E, Kappos A.J. Estimating fixed-end rotations of reinforced concrete members at yielding and ultimate. Structural Concrete, 2015. 16(4): 537-545.

54. Berry M.P, Eberhard M.O. Performance models for flexural damage in reinforced concrete columns. PEER 2003/18, Pacific Earthquake Engineering Research Center, Berkeley, CA.

55. Ghosh J, Padgett J.E Aging considerations in the development of time-dependent seismic fragility curves. Journal of Structural Engineering, 2010; 136(12): 1497-1511.

56. Rao A.S, Lepech M.D, Kiremidjian A. Development of time-dependent fragility functions for deteriorating reinforced concrete bridge piers. Structure and Infrastructure Engineering, 2016: 117.

57. HAZUS-MH MR5. Earthquake loss estimation methodology. Technical and User's Manual. Department of Homeland Security, Federal Emergency Management Agency, Mitigation Division. Washington D.C.; 2010. 
58. Alexander N.A, Chanerly A.A, Crew A.J, Bhattacharaya S. Obtaining spectrum matching time series using a Reweighted Volterra Series Algorithm (RVSA). Bulletin of the Seismological Society of America, 2014 ;104(4):1663-1673.

59. Kashani, M. M., Málaga-Chuquitaype, C., Yang, S., \& Alexander, N. A. Influence of nonstationary content of ground-motions on nonlinear dynamic response of RC bridge piers. Bulletin of Earthquake Engineering,2017; 15(9): 3897-3918.

60. Kashani M.M. Size Effect on Inelastic Buckling Behavior of Accelerated Pitted Corroded Bars in Porous Media. Journal of Materials in Civil Engineering, 2017;29:1-13.7,

61. Afsar Dizaj E, Fanaie N, Zarifpour A. Probabilistic seismic demand assessment of steel frames braced with reduced yielding segment buckling restrained braces. Advances in Structural Engineering, 2018, 21(7): 1002-1020. 